Review article

\title{
Properties, performance and associated hazards of state-of-the-art durable water repellent (DWR) chemistry for textile finishing
}

\author{
H. Holmquist ${ }^{a, *, 1}$, S. Schellenberger ${ }^{\text {b, }}{ }$, I. van der Veen ${ }^{c}$, G.M. Peters ${ }^{\text {a }}$, P.E.G. Leonards ${ }^{c}$, I.T. Cousins ${ }^{b}$ \\ a Chemical Environmental Science, Department of Chemical Engineering, Chalmers University of Technology, SE-412 96 Gothenburg, Sweden \\ b Department of Environmental Science and Analytical Chemistry (ACES), Stockholm University, SE-106 91 Stockholm, Sweden \\ c Institute for Environmental Studies (IVM), VU University, De Boelelaan 1087, NL-1081 HV, Amsterdam, The Netherlands
}

\section{A R T I C L E I N F O}

\section{Article history:}

Received 3 December 2015

Received in revised form 26 February 2016

Accepted 28 February 2016

Available online 16 March 2016

\section{Keywords:}

Hazard assessment

Per- and polyfluoroalkyl substances

PFAS

Silicones

Wax

Dendrimers

\begin{abstract}
A B S T R A C T
Following the phase-out of long-chain per- and polyfluoroalkyl substances (PFASs), the textile industry had to find alternatives for side-chain fluorinated polymer based durable water repellent (DWR) chemistries that incorporated long perfluoroalkyl side chains. This phase-out and subsequent substitution with alternatives has resulted in a market where both fluorinated and non-fluorinated DWRs are available. These DWR alternatives can be divided into four broad groups that reflect their basic chemistry: side-chain fluorinated polymers, silicones, hydrocarbons and other chemistries (includes dendrimer and inorganic nanoparticle chemistries). In this critical review, the alternative DWRs are assessed with regards to their structural properties and connected performance, loss and degradation processes resulting in diffuse environmental emissions, and hazard profiles for selected emitted substances. Our review shows that there are large differences in performance between the alternative DWRs, most importantly the lack of oil repellence of non-fluorinated alternatives. It also shows that for all alternatives, impurities and/or degradation products of the DWR chemistries are diffusively emitted to the environment. Our hazard ranking suggests that hydrocarbon based DWR is the most environmentally benign, followed by silicone and side-chain fluorinated polymer-based DWR chemistries. Industrial commitments to reduce the levels of impurities in silicone based and side-chain fluorinated polymer based DWR formulations will lower the actual risks. There is a lack of information on the hazards associated with DWRs, in particular for the dendrimer and inorganic nanoparticle chemistries, and these data gaps must be filled. Until environmentally safe alternatives, which provide the required performance, are available our recommendation is to choose DWR chemistry on a case-by-case basis, always weighing the benefits connected to increased performance against the risks to the environment and human health.
\end{abstract}

(c) 2016 Elsevier Ltd. All rights reserved.

\section{Contents}

1. Introduction $\cdot \cdots \cdot \cdots \cdot \cdots \cdot 252$

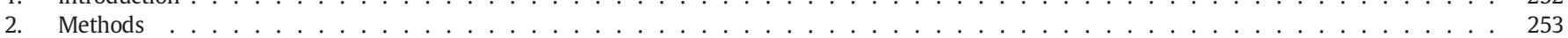

2.1. Step 1: identification of DWR chemistries . . . . . . . . . . . . . . . . . . . . . . . . . . . . . 253

2.2. Step 2: identification of relevant loss mechanisms and degradation pathways . . . . . . . . . . . . . . . . . . . . . . . . . . . 253

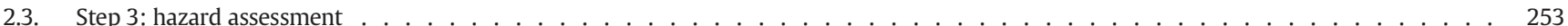

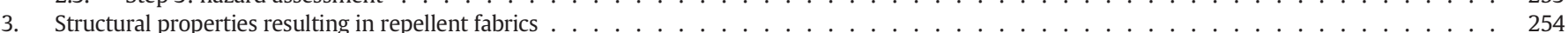

3.1. Repellent finishes based on side-chain fluorinated polymers ． . . . . . . . . . . . . . . . . . . . . . . . 255

3.2. Repellent finishes based on silicones . . . . . . . . . . . . . . . . . . . . . . . . . . . . . . . . . . 256

3.3. Repellent finishes based on hydrocarbons . . . . . . . . . . . . . . . . . . . . . . . . . . . 256

3.4. Repellent finishes based on other DWR chemistries . . . . . . . . . . . . . . . . . . . . . . . . 256

4. Diffuse emissions of DWR related substances during a garment's use-phase . . . . . . . . . . . . . . . . . . . . . . . . . . . . 257

4.1. Diffuse emissions from fabrics with side-chain fluorinated polymer DWR finish . . . . . 258

4.2. Diffuse emissions from fabrics with silicone DWR finish . . . . . . . . . . . . . . . . . . . . . . . . . 258

4.3. Diffuse emissions from fabrics with hydrocarbon DWR finish . . . . . . . . . . . . . . . . . . . . . . . . . 258

4.4. Diffuse emissions from fabrics with other DWR finishes . . . . . . . . . . . . . . . . . . . . . . . . . . . . . 258

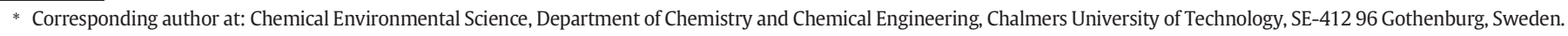
E-mail address: hanna.holmquist@chalmers.se (H. Holmquist).
}

${ }^{1}$ Holmquist and Schellenberger contributed equally to this work and share first authorship. 
5. Hazard assessment of diffusively emitted DWR related substances ． . . . . . . . . . . . . . . . . . . . . . . . . 259

6. Discussion and outlook . . . . . . . . . . . . . . . . . . . . . . . . . . . . . . . . . . . . . . . . . . 260

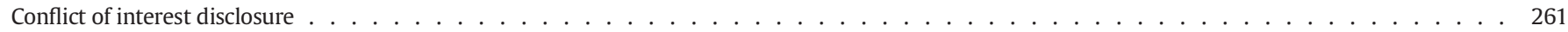

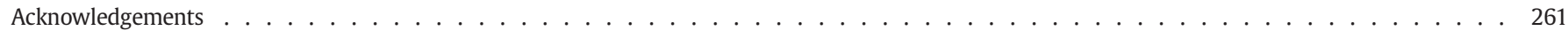

Appendix A. Supplementary data . . . . . . . . . . . . . . . . . . . . . . . . . . . . . 261

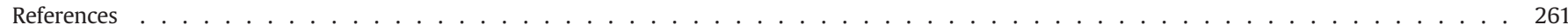

\section{Introduction}

Durable water repellent (DWR) impregnation is applied in textile finishing to impart water and, depending on impregnation chemicals, oil and stain resistance to the textile. The water repellence of the external fabric is achieved by its modification with hydrophobic polymers (Dechant, 1985), dendrimers or nanoparticles (Wong et al., 2006) and rain drops are repelled and drip off easily from a garment, thus avoiding "wet-out" (the fabric's penetration by water). Avoiding wet-out can be a comfort issue, e.g. when cycling or walking to work, but it can also be an essential protection in more extreme conditions, especially when no shelter can be reached. Wet-out can cause significant cooling of the wearer and under extreme conditions this can be life threatening. In addition, there are situations where repellency of other liquids than water becomes vitally important; like the protection against harmful liquids (e.g. acids or oils), for example in chemical production or on oil rigs. These liquids often have properties that differ from water and therefore a special DWR finish is necessary. To achieve a liquid repellent fabric a combination of surface roughness, given by the fabric itself, and a hydrophobic character, given by the DWR, is necessary. DWR agents are therefore applied as aqueous emulsions on the external fabric of a garment to deliver a non-polar fibre modification. Since only single fibres of a fabric are coated with the DWR film on a nano-metre range (see Figure S2 in the SM), the final garments have open pores which are small enough in diameter $(\mathrm{d} \sim 4 \mathrm{~nm})$ to release perspiration vapour while the external fabric withstands the penetration of much bigger rain water droplets $(\mathrm{d} \sim 100 \mu \mathrm{m})$ (see Figure $\mathrm{S} 1 \mathrm{in}$ the SM) (Mukhopadhyay and Midha, 2008).

During the last decades DWR chemistries based on polymeric perand polyfluoroalkyl substances (PFASs), more precisely "side-chain fluorinated polymers", have been common (Kissa, 2001; cited in Zero Discharge of Hazardous Chemicals (ZDHC), 2012) since side-chain fluorinated polymer DWRs are highly durable and both water and oil resistant (see e.g. Buck et al. (2011)). Polyfluoroalkyl (or possibly perfluoroalkyl) chains, usually based on either perfluoroalkanesulfonyl fluoride or fluorotelomer based chemistries, are attached to a nonfluorinated polymeric backbone. These fluorinated side chains can be severed from the polymeric chain to release PFASs and ultimately these will degrade to form highly stable perfluoroalkyl acids (PFAAs), including perfluoroalkane sulfonic acids (PFSAs) and perfluoroalkyl carboxylic acids (PFCAs), of different chain lengths. PFASs can be divided into two categories based on the perfluoroalkyl moiety chain length; long-chain and short-chain. The long-chain PFASs have been defined as having an alkyl chain containing six or more carbons in molecules that are precursors to or are PFSAs $\left(\mathrm{C}_{n} \mathrm{~F}_{2 n}+{ }_{1} \mathrm{SO}_{3} \mathrm{H}, n \geq 6\right)$ and seven or more carbons in molecules that are precursors to or are PFCAs $\left(\mathrm{C}_{n} \mathrm{~F}_{2 n}+{ }_{1} \mathrm{COOH}, n \geq 7\right)$ (Buck et al., 2011). Due to growing concern regarding the adverse effects of long-chain PFASs on human health and the environment (Filipovic et al., 2013; OECD, 2013; Vierke et al., 2012) a process of substitution of long-chain PFASs with short-chain PFASs or non-fluorinated alternatives has been started (Lassen et al., 2015; UNEP, 2012; Wang et al., 2015). Available non-fluorinated DWR chemistries include paraffin waxes, silicones, and other chemistries (including dendrimers and inorganic nanoparticles) (Namligoz et al., 2009; Schindler and Hauser, 2004; UNEP, 2012; Zero Discharge of Hazardous Chemicals (ZDHC), 2012).

This substitution process is to a large extent driven by regulations and policy actions such as the restriction of perfluorooctane sulfonic acid (PFOS) use under the Stockholm Convention (Stockholm Convention, 2014), the US Environmental Protection Agency (EPA) 2010/ 2015 perfluorooctanoic acid (PFOA) Stewardship Program (US EPA, 2013), and the identification of PFOA as a substance of very high concern (SVHC) under the EU REACH legislation (Regulation (EC) No 1907/2006) (ECHA, 2014a). In the EU (Regulation Directive 2006/122/ EC) specific regulations on PFOS levels in consumer products have been introduced; PFOS levels should be $<1 \mu \mathrm{g} / \mathrm{m}^{2}$ of the coated material in coated consumer products. In Norway regulations have further been introduced for PFOA in consumer products; PFOA levels should be $<1 \mu \mathrm{g} / \mathrm{m}^{2}$ in textiles, carpets and other coated consumer products (Klima- og miljødepartementet, 2014). Germany and Norway have submitted a proposal to ECHA (European Chemicals Agency) for an EU-wide restriction on PFOA and related substances. ${ }^{2}$ It suggests that PFOA, or any one of the listed related substances, shall not be manufactured or be placed on the market (as a chemical product or in articles) (ECHA, 2014b). PFOA has also been proposed to be listed as a POP in the Stockholm Convention (Stockholm Convention, 2015). Several of the major actors in the chemical and textile industries voluntarily phased out PFOA in 2015 (Bluesign, 2012; US EPA, 2013; Zero Discharge of Hazardous Chemicals (ZDHC), 2014).

The performance required by a fabric depends on the end-use (Zero Discharge of Hazardous Chemicals (ZDHC), 2012), therefore the variation in water and oil repellency as well as stain release between the alternative DWRs has implications for possibilities for application, as all DWRs may not be fit for all uses. Comparisons of technical performance of different DWRs are rendered difficult by the dependence not only on type of chemicals but also fabric composition and finishing technology, as well as discrepancies between laboratory testing and field trials (Gibson, 2008). With regards to the environmental performance, a number of important data gaps hindering proper risk assessment have been identified for the short-chain PFAS (Gomis et al., 2015; Scheringer et al., 2014; Wang et al., 2015). Additionally, the nonfluorinated alternatives have been studied to varying degrees, but also for these types of chemicals relevant data for hazard and risk assessment are lacking (Lassen et al., 2015; UNEP, 2012).

Diffuse emissions of chemicals from consumer products are being recognised as an important source of exposure for both humans and the environment (Molander and Rudén, 2012). With this paper we aim to evaluate the relationship between the technical performance of a DWR and its hazardous characteristics associated with diffuse releases of selected substances from the DWR finished textiles to the environment. We focus our hazard assessment on the DWR constituents that provide the water and oil repellency and not on the multiple other ingredients in DWR formulations (see methods section for justification of this approach). This overview of the trade-offs between functionality and hazards is necessary information for manufacturers involved in the currently on-going substitution process and for researchers involved in developing improved or completely new DWRs. The compound terminology used is the one proposed by Buck et al. (2011). Based on available scientific literature as well as industrial data and information, we set out to explain the complex structure-property relationships for state-of-theart DWR chemistry, the potential mechanisms for the loss of DWR chemicals from textiles and the hazards related to the diffuse emissions of selected DWR related substances. This critical review provides both

\footnotetext{
2 The proposal is still awaiting decision.
} 
industry and the research community with a road-map describing possible ways forward. It also includes identification of important data gaps that need to be filled by future research.

\section{Methods}

This critical review was executed in a stepwise process. Step 1 was the identification and evaluation of structure-property relationships of state-of-the-art DWR-technologies, Step 2 was the identification of possible mechanisms for diffuse losses of DWR related substances to the environment for the respective technologies, and Step 3 was a hazard assessment for selected DWR related substances. Finally, the combined output of Step 1-3 was evaluated in a discussion of DWR performance in relation to customer needs and related hazards.

The terminology related to DWR as used in this article is defined in the Supplementary Material (SM).

\subsection{Step 1: identification of DWR chemistries}

Since the research on waterproof and breathable fabrics is of high commercial interest, information about exact structures of commercialised DWRs are proprietary and only limited open literature is available.

Therefore, a combination of information search procedures, including literature search in databases of peer-reviewed literature, patent databases and interviews with raw material producers, was implemented and is further explained in Table 1.

\subsection{Step 2: identification of relevant loss mechanisms and degradation pathways}

Relevant loss mechanisms of DWR related substances from a DWRtreated fabric (i.e. mechanism giving rise to diffuse emissions), including leaching to water, evaporation to air as well as possibilities for release of DWR related substances by wear and tear, were identified in the literature, and evaluated for the DWR chemistries as identified in Step 1 above (see Fig. 2). Likewise, degradation mechanisms governing diffuse releases by precursor transformation were evaluated for precursors identified as relevant for leaching, evaporation and/or wear and tear. Focus was on the use-phase of a DWR-finished fabric although many of the mechanisms described are substance dependent (e.g. evaporation occurs for volatile substances etc.) and thus also applicable for diffuse releases during the end-of-life phase of the fabric.

\subsection{Step 3: hazard assessment}

DWR related substances were selected for hazard assessment based on two criteria, against which the results obtained in Step 1 and 2 were evaluated: i) the substance is related to (i.e. a degradation product of or an impurity in) the structural moiety of the polymer, dendrimer or nano-particle, that provide the water (and oil) repellency function to the DWR formulation (the chemical mixture applied in fabric finishing), and at the same time ii) the substance has potential to be released from the fabric to the environment during the use-phase of the fabric. From the rather large amount of substances meeting these criteria (i.e. polymers, impurities and degradation products) the most relevant substances for a representative hazard assessment were selected for each of the four broad groups of DWRs described here. This selection was made by expert judgement aiming to select the substances contributing most to the hazards within the respective groups.

The selection procedure limited the scope of the assessment. Application of the first criteria (i) results in exclusion of a large number of substances that could also be part of a DWR formulation as ingredients or impurities or generated through degradation processes, but not directly related to the water (and oil) repellent structural moiety. Examples are cross-linkers, extenders and catalysts as well as the structural basis such as a dendritic polyurethane (PUR) backbone or the nanoparticle. As such the hazard assessment does not provide a complete

Table 1

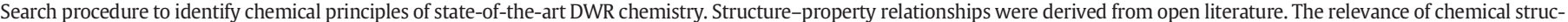

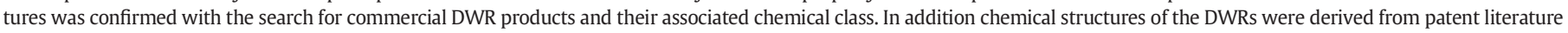
using different indicators to prove their commercial relevance.

\begin{tabular}{|c|c|c|}
\hline Source & Approach & Result \\
\hline $\begin{array}{l}\text { Databases of peer-reviewed } \\
\text { literature }\end{array}$ & Identification of DWR chemistry studies from academic sources. & Structure-property relationships. \\
\hline Brand websites & $\begin{array}{l}\text { Internet search for commercial DWR brands Technical Datasheet (TDS); } \\
\text { Material safety data sheet (MSD); application procedures }\end{array}$ & Identified brands and general chemistry of DWR technologies. \\
\hline Patent databases & $\begin{array}{l}\text { Combined search: } \\
\text {-Espacenet } \\
\text {-Depatisnet }^{\mathrm{b}} \\
\text {-Google patents } \\
\text { Search term: } \\
\text { "repellent textile" } \\
\text { Indicators of relevancy: } \\
\rightarrow \text { number of citations } \\
\rightarrow \text { patents that are cited in other patents should be relevant } \\
\rightarrow \text { number of patents in the field } \\
\rightarrow \text { patent relevancy because of a high activity (productivity) of inventor } \\
\text { (company) } \\
\rightarrow \text { patent family size } \\
\rightarrow \text { patents, which are logged in many countries should be more relevant }\end{array}$ & $\begin{array}{l}\text { General structures of commercial DWR formulations. } \\
\text { Number of relevant patens reviewed: } 180 \text {. }\end{array}$ \\
\hline Raw material producers & Interviews with representatives from the major raw material producers. & $\begin{array}{l}\text { Companies interviewed: } 8 \\
\text { Information about performance requirements; principle } \\
\text { of production process. } \\
\text { Confirmation of derived structure-property relationships } \\
\text { for DWRs from academic literature and patents. }\end{array}$ \\
\hline
\end{tabular}

a Patent database with 90 million patent documents worldwide, containing information about inventions and technical developments.

b German patent database with access to 41 million documents worldwide.

c Patent search engine with applications from the United States Patent and Trademark Office (USPTO), European Patent Office (EPO), and World Intellectual Property Organization (WIPO); 8 million documents. 
picture of all hazards connected to the DWR formulations but highlights relevant hazards in the respective groups that are connected to the chemistry providing water (and oil) repellency. We justify this limitation of scope by arguing that, irrespective of other hazardous substances contained in or generated from the DWR formulations, the chemical moiety providing water (and oil) repellent function is key when assessing alternative DWRs, as other moieties may be substitutable. Application of the second criteria (ii) means that the hazard assessment is valid for diffuse emissions and we further limit the assessment to effects relevant for exposure via the environment, i.e. we exclude also the sensitisation and irritation endpoints from the assessment (see below).

The hazard assessment criteria as laid out in the program: Design for the Environment Alternatives Assessments (US EPA, 2011) were used as basis for the hazard assessment. This is the U.S. Environmental Protection Agency's alternatives assessment tool to evaluate chemicals based on their human health and environmental hazards (a program related to the Safer Choice label). It was chosen as the hazard assessment tool for this review since it is to a large extent based on the United Nation's Globally Harmonised System (GHS), i.e. internationally accepted hazard criteria. In addition, it bears many similarities with the GreenScreen method (Clean Production Action, 2014), which is used by several actors in the DWR industry. In the hazard assessment the intrinsic characteristics of a substance are evaluated according to the criteria of the method. Human and environmental exposure is not considered, thus to understand the risks connected to the substances being studied the hazard assessment would need to be combined with an exposure assessment. The method builds on 16 hazard endpoints and was modified to suit the purpose of our work by removal of the sensitisation and irritation/ corrosivity endpoints (Table 2), since these are less relevant for environmental exposure. The hazard endpoints deemed especially relevant for the purpose of evaluating hazards connected to diffuse environmental emissions of DWR related chemicals were chronic human health, ecotoxicology and fate. This is due to the fact that diffuse emissions give rise to continuous exposure rather than intermittent exposure peaks and thus only chronic toxicity is likely to manifest via environmental exposure. Acute endpoints were still kept in the assessment to support places where chronic data are lacking. For the ecotoxicology endpoints, focus was placed on aquatic toxicology but data on terrestrial species were described when such data were found. Endpoints such as eutrophication, global

\section{Table 2}

Hazard endpoints of the DfE method and corresponding hazard designations. The verbal hazard scale includes the terms very low, low, moderate, high and very high. The number of hazard designations available vary between endpoints. If data are not sufficient for classification the endpoint is designated a data gap (DG).

\begin{tabular}{ll}
\hline Category and endpoint & Hazard designations \\
\hline Human Health & \\
Carcinogenicity (C) & Very high-low \\
Mutagenicity \& genotoxicity (M) & Very high-low \\
Reproductive toxicity (R) & High-very low \\
Developmental toxicity (D) & High-very low \\
Endocrine activity (E) & Potentially endocrine active (PEA) or No \\
& evidence of endocrine activity (NEEA) \\
Acute toxicity (AT) & Very high-low \\
Repeated dose toxicity (ST) & High-low \\
Neurotoxicity (N) & High-low \\
Ecotoxicology & \\
Acute aquatic toxicity (AA) & \\
Chronic aquatic toxicity (CA) & Very high-low \\
Other ecotoxicity studies when available & Very high-low \\
& Very high-very low \\
Fate & \\
Persistence (P) & Very high-very low \\
Bioaccumulation (B) & Very high-low \\
\hline
\end{tabular}

a Criteria available only for avian species and bees and have not been applied in the present study. warming which are also mentioned in the DfE guidance (US EPA, 2011), were not assessed at all.

The assessments were based on a "precautionary principle", meaning that worst case assumptions have been made when data were ambiguous. Each classification was given a confidence score (high or low) where low confidence indicates that the hazard classification is uncertain and that it could be changed to either higher or lower hazard with additional data (in addition to this general rule, the principles for determining the level of confidence, outlined for the GreenScreen chemical hazard assessment procedure, were followed (Clean Production Action, 2013)). The DfE guidelines prescribe use of data from suitable analogues and estimated data from appropriate models if measured data on the chemical being evaluated are lacking. In order to clearly highlight data gaps we chose to only use measured/laboratory data for the chemicals being evaluated in the hazards assessments within this critical review, with the exception that estimated log $\mathrm{K}_{\mathrm{ow}}$ were used as basis for bioaccumulation assessment if measured data were missing (this is justified by the fact that it is one of the oldest and most established methods in structure activity modelling). Where data used for the assessments come from secondary sources that used estimation methods this is indicated in the SM and Table 3. The DfE guidelines leave it open if no-effect or effect levels are to be compared with the criteria. In this review, in analogy with GHS, the human health endpoint criteria were compared with the dose giving significant effects and ecotoxicological endpoint criteria were compared with $\mathrm{E} / \mathrm{LC}_{50}$ values (acute toxicity) and no observed effect concentration (NOEC) (chronic toxicity). When the range between the NOAEL and the LOAEL overlapped the criteria and no other data were available to support classification the lowest observed adverse effect level (LOAEL) was compared with the criteria and the classification was given a low confidence score (relevant for the human health endpoints).

The basis for the assessment included peer-reviewed articles, industry-generated data as presented in safety data sheets (SDS) and available reports as well as policy documentation available via e.g. ECHA and OECD. The Elsevier Scopus ${ }^{\circledR}$ citation database was used as the primary source of scientific literature. Industry-generated data were obtained via websites and direct contact with industry representatives. Complete reference lists and data commentary to hazard classifications are available in the SM.

\section{Structural properties resulting in repellent fabrics}

In this section the critical review aims to summarise the most important structure-property relationships of commercially available DWRs. Depending on the end-uses of textiles, different polymer architectures are required. However, all DWRs are based on comparable structural elements regarding their functionality within the textile. State-of-the-art DWR polymers have hydrophobic side chains linked to a polymer backbone (see Fig. 1a-c) or dendrimers or inorganic particles (see Fig. S6 in the SM). These non-polar sidechains are based on hydrocarbons (Dechant, 1985), silicones or per- and polyfluoroalkyl moieties (Kissa, 2001) and need to be closely packed and orientated towards the fibre surface to achieve an "umbrella-like" repellent effect.

Since terminal $\mathrm{CF}_{3}$ (side-chain fluorinated polymers) and $\mathrm{CH}_{3}$ groups (hydrocarbon- and silicone-based polymers) are the most hydrophobic groups (lowest critical surface energy $\gamma_{c}$ ) in organic chemistry, the best repellency results from a dense molecular packing of these groups on the fibre surface. All DWRs function according to these structural principles. Therefore, it is beneficial that the hydrophobic side chains stay closely packed together (Wang et al., 1997) because changes in conformation would bring less hydrophobic groups to the fibre surface (e.g. $\mathrm{CF}_{2}, \mathrm{CH}_{2}$ with higher critical surface energy $\gamma_{c}$ ) which would reduce the repellency of the textile. Additionally, a certain length of hydrophobic side-chains is 


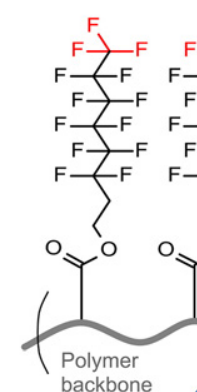
$F \geq_{F}^{F} F \geq_{F}^{F} F \sum_{F}^{F} F$ $\mathrm{F} \sum_{\mathrm{F}} \mathrm{F} \mathrm{F}_{\mathrm{F}} \mathrm{F} F \mathrm{~F}$ $\sum_{F}^{F} F \perp_{F}^{F} F \sum_{F}^{F} F$
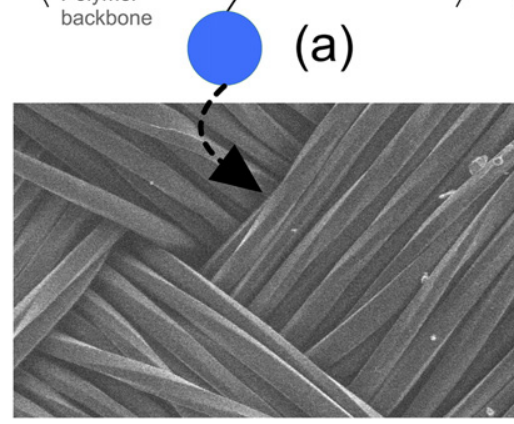

\begin{tabular}{|c|c|c|}
\hline & Group & $\gamma_{c}[\mathrm{mN} / \mathrm{m}]$ \\
\hline & $\mathrm{CF}_{3}$ & 6 \\
\hline & $\mathrm{CF}_{2}$ & 18 \\
\hline & $\mathrm{CH}_{3}$ & 22 \\
\hline & I $\mathrm{CH}_{2}$ & 31 \\
\hline
\end{tabular}

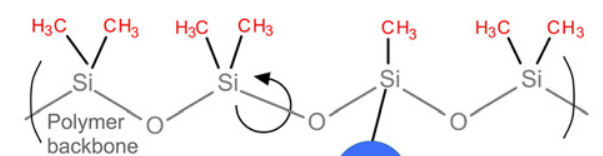

(b)

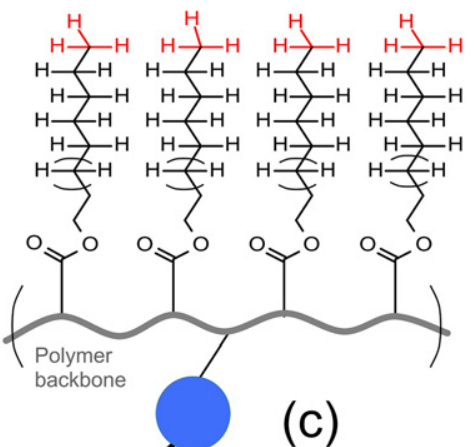

(c)

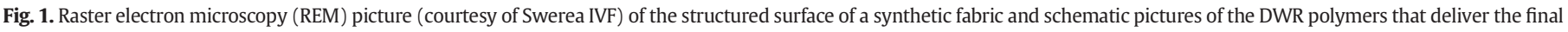

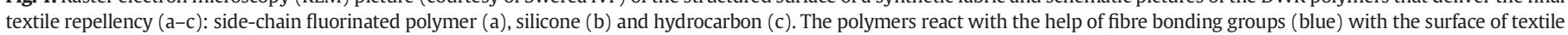
fabrics. Terminal groups with low critical surface energy $\left(\gamma_{c}\right)$ (Fox and Zisman, 1950), $\mathrm{CF}_{3}$ and $\mathrm{CH}_{3}$ groups, need to be closely packed and orientated toward the fibre surface.

necessary to shield the fabric against polar water droplets (Honda et al., 2005; Zero Discharge of Hazardous Chemicals (ZDHC), 2012).

It is important to point out that the water repellency is not an isolated property but part of combination of various functions that textiles have to fulfil. In addition to the repellent properties, the durability of this effect is an important aspect of DWRs. For the purpose of durability the DWR polymers have to be attached to the fibre surface via physical or chemical bonding. Therefore DWRs contain fibre bonding groups such as hydroxyl, epoxy or vinyl groups linked to the polymer backbone (see Fig. 1) that react either directly or indirectly, with help of cross-linkers (e.g. diisocyanates), with the fabrics. Older DWRs used physical binding such as the polar interactions of carboxylates [ $\mathrm{R}^{-\mathrm{COO}^{-}}$] with metal or hydrogen binding for the surface linkage (see Fig. S5a in the SM). These intermolecular forces alone are not suitable to form stable DWR finishes that can withstand the conditions of everyday use (washing, weathering or abrasion). Modern DWRs are therefore modified with functional groups that react covalently with addressable surface groups. In case of a lack of reactive bonding sites on the fibre (e.g. polyethylene, polypropylene), additional reactive groups can be introduced by plasma treatment (Morent et al., 2008; Shishoo, 2007). The durability of the DWR finish can be achieved with the covalent cross linking of the polymers to the fibre surface. Durability can also be achieved by creating a crosslinked network of the DWR on the fibre surface (envision each fibre surrounded by netting) that is not covalently bonded. Covalent bonding of the DWR polymer to the fibre surface is therefore not a requirement for durability (see Figure 2 in the SM).

In industrial finishing processes DWR polymers are generally applied as water-based emulsions through a padding process (Speke, 1954). Thereby the untreated fabrics are immersed in an application bath (Kissa, 2001) (see Table S1) with the DWR polymers and squeezed in a "foulard" (device for textile treatment with two rollers) to remove the excess liquid to the needed concentration of DWR-polymer on the fabric (Schindler and Hauser, 2004) (wet pick-up). After this adsorption of DWR polymers to the fibre materials a curing step in an oven promotes the crosslinking reaction of the fibre reactive groups with the bonding sites on the fabric (Schindler and Hauser, 2004). The process to form a permanent hydrophobic layer on fibre materials is very complex and depends on the structure and chemical nature of the individual fabrics. The end-performance of a DWR finished fabric is dependent on (1) the fibre type, (2) the fabric construction (e.g., knit, weave, multilayer), (3) fabric preparation and (4) the DWR chemistry used. Furthermore, application process conditions as well as processes that occur after DWR application (e.g., stone-washing, calendaring, embossing) have an influence.

\subsection{Repellent finishes based on side-chain fluorinated polymers}

DWRs based on per- or polyfluoroalkyl side chains are the most effective water repellent (hydrophobic) finishes for textiles and are unique in that they can additionally deliver lipo- or oleophobic properties. The fluorinated side-chains comprise an alcohol moiety which is bonded via an ester linkage to non-fluorinated polymeric backbone and can typically be $\mathrm{n}: 2$ fluorotelomer alcohols ( $\mathrm{n}: 2$ FTOHs: $\mathrm{C}_{\mathrm{n}} \mathrm{F}_{2 \mathrm{n}}+{ }_{1} \mathrm{CH}_{2} \mathrm{CH}_{2} \mathrm{OH}$, where $\mathrm{n}: 2$ means that $\mathrm{n}$ perfluorinated carbons are attached to 2 non-fluorinated carbons (ethyl alcohol group) and $\mathrm{n}$ is typically $4,6,8$ or 10 ) or perfluoroalkane sulfonamidoethanols,

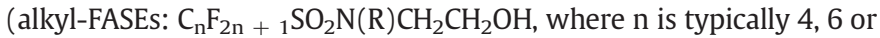
8 and $\mathrm{R}$ is $\mathrm{CH}_{3}, \mathrm{C}_{2} \mathrm{H}_{5}$, or another alkyl group). These side-chain fluorinated polymer finishes are mostly based on acrylic, methacrylic (Franchina, 2002; Robert and Stuart, 1970; Robert, 1996) (see Fig. S3 in the SM) or polyurethane backbones and are copolymerised with non-fluorinated monomers. In similarity to the study of Castelvetro et al. (2002) these non-fluorinated monomers have functionalities like rheology control or influence the glass transition temperature. In addition the dispersion stability can be influenced by the introduction of water soluble groups (Castelvetro et al., 2002).

While the non-fluorinated DWR technologies are structurally comparable to fluorinated DWR technologies, per- and polyfluoroalkyl side-chains offer outstanding repellency of both polar and non-polar liquids. Therefore fluorinated DWR technologies are widely used in 
textile applications with high performance requirements. The strong liquid repellency can be explained by the dense packing, rigidity and hydro- and oleophobic nature of per- and polyfluoroalkyl chains, which is a result of the radii and high electronegativity of fluorine atoms attached to the carbon chain. Since the van der Waals radius $(R)$ of fluorine is higher than the radius of hydrogen atoms $\left(\mathrm{nm} ; \mathrm{R}_{\mathrm{F}}=\right.$ $1.46 \mathrm{~nm}$ and $\mathrm{R}_{\mathrm{H}}=1.10$, respectively) (Batsanov, 2001) the perfluoroalkyl moieties in the alkyl chains form a twisted helical structure (Fournier et al., 2011) where the fluorine atoms form a dense sheath around the carbon skeleton (Esumi and Ueno, 2003). The combination of rigidity and even distribution of the electron density (symmetrical attraction of electrons by the electronegative fluorine atoms around the carbon chain) results in a minimum of intermolecular interactions between the copolymer side chains of fluorinated DWRs. Therefore these groups can form highly packed and extremely hydro- and oleophobic polymer domains (Wang et al., 1997) that point outwards from the fibre surface and result in excellent liquid repellency. Since the rigid rod-like structures differ in their physicochemical behaviour from the relatively flexible alkyl chains in hydrocarbon and silicone DWR polymers, fluorinated DWR polymers can also repel non-polar liquids (Hegemann, 2005). The high packing of per- and polyfluoroalkyl side chains, caused by fluorophilic interactions (Skotheim, 1997), strongly depends on the length of the perfluoroalkyl moieties (see Fig. S3b in the SM). An optimal packing with crystallised side-chains, which results in an exceptional repellency of the DWR finish occurs for per- and polyfluoroalkyl chains with more than eight perfluorinated carbon atoms (Scheirs, 1997). Since the phase-out of materials based on long-chain PFAS, stateof-the-art side-chain fluorinated polymers are based on a defined perfluoroalkyl chain length of four (Renner, 2006) or six (Z. Wang et al., 2013; Zero Discharge of Hazardous Chemicals (ZDHC), 2012) perfluorinated carbon atoms. These short-chain side-chains are non-crystallising but they nevertheless form relatively highly packed hydro- and oleophobic domains. Thus, it is still possible to produce water, oil and stain repellent garments with high performance levels.

\subsection{Repellent finishes based on silicones}

Another class of finishes (see Fig. S4 in the SM) with high water repellency are based on a polydimethylsiloxane (PDMS) backbone [-Si $\left(\mathrm{CH}_{3}\right)_{2} \mathrm{O}-$ ]. In addition to the hydrophobic character of the PDMS chain, fabrics treated with these types of DWR polymers result in finishes with a soft feel to the hand. This special characteristic can be explained by the structure of the polysiloxane backbone, which is the most flexible chain known in polymer chemistry (Mark, 2004). The Si-O-Si bond angle (Fig. S4 in the SM) can undergo variations from 105 to $180^{\circ}$. Additionally the relatively long $\mathrm{Si}-\mathrm{O}$ and $\mathrm{Si}-\mathrm{C}$ bond provide an increased spatial separation of the neighbouring hydrophobic methyl substituents (Jones, 1995). The combination of flexibility and long molecular bonds permits an easy change in polymer conformation and $\mathrm{CH}_{3}^{-}$groups can freely rotate around the $\mathrm{Si}-\mathrm{O}-\mathrm{Si}$ backbone.

The structural properties of silicones facilitate the formation of a repellent durable film on the fibre materials. The hydrophobic methyl groups on the siloxane backbone will orientate away from the fibre surface fabric, while the fibre bonding is realized between the hydrophilic (Frolov et al., 1992) O-Si-O chain and polar surface groups. Due to the difference in electronegativity of silicon and oxygen atoms, hydrogen bonding occurs between surface groups that carry electropositive hydrogen atoms and the $\mathrm{O}-\mathrm{Si}-\mathrm{O}$ chain. Besides this relatively weak intermolecular interaction, several reactive groups can be introduced in the siloxane chain [organoreactive polysiloxanes; $-\mathrm{Si}\left(\mathrm{CH}_{3}\right)_{2} \mathrm{O}-\mathrm{Si}\left(\mathrm{CH}_{3}\right) \mathrm{X}-$ $\mathrm{O}-$; where $\mathrm{X}$ is the fibre reactive group] to form covalent bonds with the reactive groups on the fibre surface and increase the durability of the DWR finish. Si-H groups can react thereby either directly or as hydrolysed hydroxyl groups that can undergo a reaction with cross linkers such as diisocyanates. Despite some of the advantages of silicones (e.g. soft feel and water repellency), the majority of these DWR-types have only a moderate durability to laundering and no (unmodified) silicone DWRs can deliver oil repellency. DWRs based on PDMS can be additionally modified with per- or polyfluoroalkyl side chains (Ludemann et al., 1991). These hybrid systems have similar properties to PDMS-based DWRs, but the addition of per- and polyfluoroalkyl chains can result in an additional oil and soil repellency of the finished fabric.

\subsection{Repellent finishes based on hydrocarbons}

In DWRs based on hydrocarbons (see Fig. S5 in the SM) crystallised linear n-alkyl chains $\left[-\left(\mathrm{CH}_{2}\right)_{\mathrm{n}}-\mathrm{CH}_{3}\right]$ are used to achieve water repellency. This resembles the natural low energy surfaces of plant leaves (Barthlott and Neinhuis, 1997; Koch and Ensikat, 2008) that develop repellency with crystalline wax tubules (Dora and Wandelt, 2011). The dense packing of the paraffinic alkyl groups in DWRs strongly depends on alkyl chain length and the structure of the polymeric backbone. The first formulations were based on a blend of paraffin compounds and metal salts of fatty acids (Fig. S5a in the SM) (Schindler and Hauser, 2004). The linkage between the DWR agent and the fabric is thereby accomplished via ionic bonding of the polar carboxylates to the fibre surface. The alkyl chain of the fatty acid promotes non-polar interactions with the paraffinic part that has non-polar bonding groups. The resulting crystallisation process of hydrophobic moieties is essential for the water repellency of the finished fabric. It is favourable to use compounds with linear alkyl chains because branching reduces the crystallisation behaviour. The poor durability of these physical bonding waxes during laundering or dry cleaning (Kissa, 2001) has led to the development of more stable DWRs like melamine-based resins (Fig. S5b in the SM). Melamine can form stronger covalent bonds with the fibre surface. Their branched structure allows the introduction of N-methyl groups that can be cross-linked with the fibre surface while hydrophobicity is realised with terminal groups based on stearic acid (Archroma, 2014).

Modern hydrocarbon DWRs consist of acrylic copolymers (Fig. S5c in the SM) where different copolymer blocks deliver the necessary functions of durability and repellency (Fuchs et al., 2010). Through the choice of different polymerisation conditions, the polymer can be tailor-made for the requirement of different textiles. The water repellent block of the copolymers consists of n-alkyl groups that extend from the backbone of the molecule. Side-chain crystallisation occurs from a chain length higher than 12 carbons for methacrylate and a chain length higher than eight for acrylate backbones (Greenberg and Alfrey, 1954).

Other DWR developments are the encapsulation of waxes which has the advantage of providing an improved homogeneous distribution of DWR droplets on the fabric. In these systems wax compounds are encapsulated in a polymer core that is released during the curing step. The advantage of this application is that the liquid wax does not penetrate deeply into the fibre and stays at the air-fibre interface, reducing the amount of DWR that is used. Other hydrocarbon DWR developments made from renewable resources are based on fatty acids from plant extracts (Lang, 2015; LJ-specialities, 2015). Although these newly developed hydrocarbon DWR finishes have good water repellency they cannot deliver oil repellency.

\subsection{Repellent finishes based on other DWR chemistries}

Dendrimeric DWRs (see Fig. S6 in the SM) are based on hyperbranched polymeric structures that consist of ester or polyurethane segments (Tang et al., 2010). They are synthesised in a multistep synthesis and emulsified in water. During drying on the textile the highly branched polymers self-organize forming a continuous polymeric film on the surface. The addition of the dendrimeric surface 
structure on the fibre materials can deliver an increased repellent effect that is comparable to the hierarchical micro and nanostructure of the lotus plant (Spori et al., 2008). Since these highly branched polymers self-assemble in a polymeric film on the fibre surface, these materials do not contain nanoparticles. The surface of dendrimers can be modified with fatty acids, per- or polyfluoroalkyl groups or polyalkylsiloxanes to achieve repellent properties (Möller, 2009) (see Fig. 6 in SM). Free hydroxyl surface or epoxy groups can function as cross-linking points to achieve covalent bonds with the fibre surface (Hu et al., 2007). Inorganic nanoparticle DWRs also mimic the repellent nanostructures of lotus plant leaves and are based on spherical inorganic particles at the nanoscale (1-100 nano-metres in size) that can increase the surface area of the treated fabric (Zhang et al., 2003) (Fig. S6 in the SM). They are manufactured using inorganic materials (Feng et al., 2014; Iverson and Rudat, 2010) like $\mathrm{SiO}_{2}$ or $\mathrm{Al}_{2} \mathrm{O}_{3}$ (see Fig. S6 in the SM). Inorganic nanoparticle surfaces are also modified to provide hydrophobicity and cross-linking points to the fibre surface (Su and Li, 2010) (see Fig. S6 in SM).

\section{Diffuse emissions of DWR related substances during a garment's use-phase}

Most of the DWR finished garments undergo a reduction in repellency during the textile's lifetime (Arunyadej et al., 1998; Leonas, 1998). The change of this macroscopic material property is a clear argument for the loss of chemicals from DWR finished fabrics and several mechanisms are conceivable. Fig. 2 shows possible scenarios for the loss of chemicals from a garment. Loss processes can occur from the surface of the fabric or from fragments like fibres (Abdullah et al., 2006) or particles into the environmental compartments. The increased surface area of these material fragments (Abdullah et al., 2006; Browne et al., 2011; Özdil et al., 2012) can result in faster loss rates. Rough surfaces like DWR finished cotton fabrics might have a higher tendency for abrasion and fragment formation than the smooth surfaces of synthetic fibres (Hu, 2008). The surface morphology of spherical nano and dendrimeric DWRs could have an additional influence depending on the chemistry of hydrophobic modification (Fig. S6 in the SM); the higher surface area of these "structured" fibre treatments might increase the speed of degradation processes. Moreover the type of linkage between the DWR compound and fibre surface will have a strong impact on loss rates. Non-covalently attached chemicals like residuals from production or non-reacted monomers can be released during laundering, washed out by rain that penetrates the fibre surface or, depending on their volatility be lost to the air. Polymer degradation and the related breakage of covalent bonds could be another mechanism for the loss of chemicals from garments with DWR finish. Various factors can cause polymer stress during its lifecycle (Bresee, 1986). The degradation is facilitated by the presence of hydrolysable and oxidisable groups and a balance of hydrophobicity and hydrophilicity. The rate of degradation depends on the physical properties such as surface area, morphological properties, crystallinity and polymer orientation (Chiellini and Solaro, 2003) of the DWRs. The primary processes for the degradation of DWR polymers might be hydrolysis and photo-oxidation (Kawai, 1995). UVdegradation of DWR polymers (Sung et al., 2004) can result from the exposure to sunlight and is dependent on the radiation intensity. This process however, can only take place if photoactive groups (e.g. carbonyl) are present in the polymers backbone that absorb light under terrestrial conditions $(\lambda>290 \mathrm{~nm})$. An important requirement for hydrolysis to occur during laundering is the accessibility of positions on the polymers for degradation (e.g. ester bonds), under the conditions in which the textiles are used. Since hydrophobic moieties like $\mathrm{CH}_{3}$ and $\mathrm{CF}_{3}$-groups form a hydrophobic shield around the DWR backbone, the point of degradation could be inaccessible, especially in the presence of polar reactants like hydroxyl radicals. The chemical nature of degradation products and their degradation rates depends on the chemical class of the DWR agent.

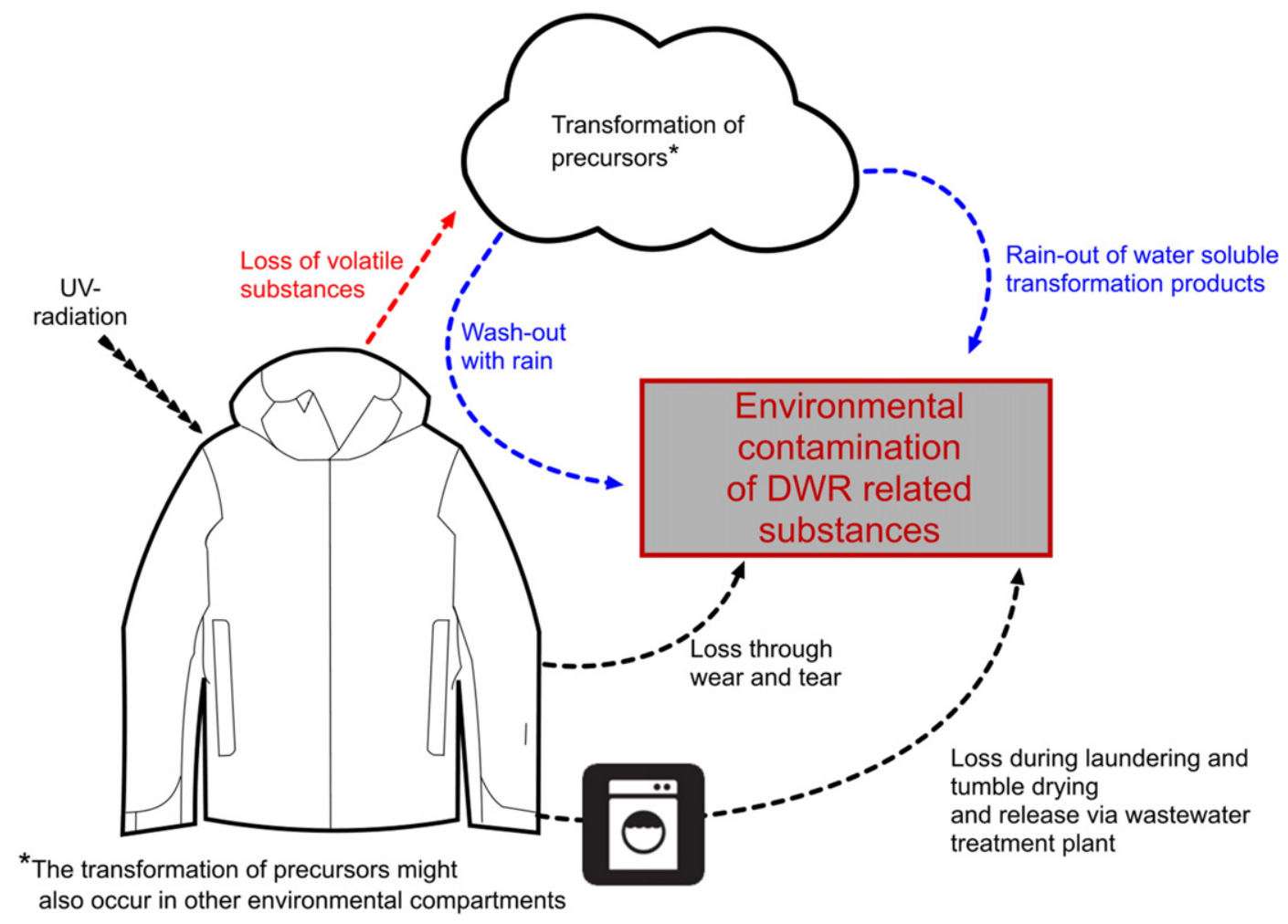

Fig. 2. Possible mechanisms (simplified) for loss of chemicals from DWR finished fabrics during the use phase (see Fig. S7 in the SM for a more detailed explanation). 
Furthermore, reimpregnation of garments (Casper, 2014) to "refresh" the textiles initial performance can be an additional factor for chemical loss. Specially designed fluorinated (3M, 2013; K. Chemie, 2015) or non-fluorinated (Benzema, 2015; R. Chemie, 2015), reimpregnation agents are added in the washing process, or as aerosol sprays, and bind, depending on the chemical structure either physically (non-permanent) or chemically (permanent) to the fabric. This process is very often used in work wear (Thumm, 2015) and protective clothing (Freeston, 1981). Especially non-permanent reimpregnation agents will be prone for chemical release.

\subsection{Diffuse emissions from fabrics with side-chain fluorinated polymer DWR finish}

Several studies (Berger and Herzke, 2006; Dinglasan-Panlilio and Mabury, 2006; Dreyer et al., 2014; Hanssen and Herzke, 2014; Herzke et al., 2012; Knepper et al., 2014; Santen and Kallee, 2012a,b; Schlummer et al., 2013) demonstrate the loss of residual PFASs (i.e. impurities; e.g., FTOHs, alkyl FASEs, PFAAs) from textiles and thus prove the relevancy of these loss mechanisms. However, according to the producers of state-of-the-art side-chain fluorinated polymer DWRs, the amount of PFAS residual impurities, e.g. PFOA, can be reduced to the ppb concentration range and producers were committed to achieve these reductions under the US EPA 2010/2015 PFOA Stewardship Program (Daikin, 2016; Rudolf Group, 2016). By 2014 the companies taking part in the Stewardship programme reported reduction in product content of PFOA, its precursors, and higher homologues in fluoropolymer dispersions, other fluoropolymers and telomer-based products, to 94-100\%, depending on product type and company (US EPA, 2014). Actual concentrations of perfluoroalkyl carboxylic acid (PFCA) residues were reported by a few companies and were between $<0.5-500 \mathrm{ppb}$ (Daikin, 2016; Rudolf Group, 2016).

If degradation of side-chain fluorinated polymer DWRs occurs this would result in the release of PFAS, and eventually terminal degradation products, such as PFCAs (Frömel and Knepper, 2010; Liu et al., 2007; Liu and Mejia Avendaño, 2013; Rankin, 2015; Wang et al., 2009). They may be released as a result of cleavage of the acrylic ester or polyurethane linkage that links the per- or polyfluoroalkyl side chains to the carbon backbone. The acrylic ester linkage is estimated to be more stable than the corresponding polyurethane bond (Russell et al., 2010). Important degradation products of this degradation pathway could be PFOA for long-chain $\mathrm{C}^{3}$-DWRs and perfluorohexanoic acid (PFHxA) (C6) and perfluorobutane sulfonic acid (PFBS) (C4) for the state-of-the-art short-chain PFAS-based DWRs. Several research groups investigated the degradation of fluorotelomer-based acrylate polymers (FTACPs) in aerobic soils as a potential source of PFCAs to the environment. These polymer particles might be related to fibre fragments that can be released from garments with side-chain fluorinated polymer DWR finishes. A study in soil by Washington et al. (2009) on degradation of grained FTACPs estimated degradation half-lives of 870-1400 years. Furthermore a reduced half-life of 10-17 years was modelled for particles that were 300 times smaller assuming that the degradation is surface mediated. In a follow up study soil half-lives of commercial FTACPs, placing large efforts to minimise effects of residuals on the results, soil degradation half-lives were determined to be 33-112 years (Washington et al., 2015). A study by Rankin et al. (2014) with a synthesised FTACP (free of residuals, i.e. no interference with degradation measurements) of lower molecular weight $(\sim 3000 \mathrm{~g} / \mathrm{mol})$ reported half-lives of 8-18 years while a study from Russell et al. (2008) reported half-lives of 1200-1700 years with a commercial FTACP (including residuals) of higher molecular weight ( 40,000 g/mol). Russell (2015)

\footnotetext{
${ }^{3}$ C8-DWR denotes 8 carbons in the perfluoroalkyl side chains in the side chain polymer DWR, C6 denotes 6 carbons and C4 denotes four carbons.
}

gave an overview of the findings of the studies described above and we would summarise his conclusions relevant for this review as follows: commercial polymers do degrade in the environment, albeit at a slow rate and depending on the polymer size and weight as well as environmental conditions, and half-lives of commercial polymers (high molecular weight) are expected to be in the range of $100 \mathrm{~s}-$ 1000s years and that low molecular weight polymers degrade with half-lives of 10s of years. Degradation of FTACPs can thus be expected, but due to the high variability of these results, an exact prediction of degradation times of FTACPs is currently not possible.

\subsection{Diffuse emissions from fabrics with silicone DWR finish}

Various types of silicone polymers based on PDMS have been shown to contain residual levels of cyclic volatile methyl siloxanes due to residues from manufacturing processes; e.g. octamethylcyclotetrasiloxane (D4) (430-3360 ppm) (Brooke et al., 2009b) and decamethylcyclopentasiloxane (D5) (570-3110 ppm) (Brooke et al., 2009a). The closest analogue to the highly functionalised silicone products that can be used as DWR formulations is PDMS in its different functionalised forms (R. Maecker, 2015). DWR formulations based on silicones could contain D4 and D5 (R. Maecker, 2015). These substances are stripped-off (R.M. Maecker, 2015) after the formation of high molecular weight DWR silicone products (PDMS based) ( $R$. Maecker, 2015), and the levels of D4 and D5 in silicone DWR formulations are expected to fall in the range of several hundred to several thousand ppm (Lehotkay, 2015; R. Maecker, 2015), which is in approximate agreement with levels published for other PDMS based silicone products (Brooke et al., 2009a,b). Furthermore, leftover cyclic residuals should evaporate during the curing in the fibre treatment process meaning that D4 and D5 residual levels are expected to be lower in the finished products.

Studies on related PDMS polymers showed a relatively fast depolymerisation process by hydrolytic degradation in soil (Graiver et al., 2003; Lehmann et al., 2000). Thereby silanols [ $\left(\mathrm{Si}\left(\mathrm{CH}_{3}\right)_{3} \mathrm{O}\right)-$ $\left.\left(\mathrm{Si}\left(\mathrm{CH}_{3}\right)_{2} \mathrm{O}\right)_{\mathrm{n}}-\mathrm{Si}\left(\mathrm{CH}_{3}\right)_{2}-\mathrm{OH}\right]$ of lower molecular weight are formed and further hydrolysis predominantly proceeds to yield dimethylsilanediol (DMSD) and trimethylsilanol (TMS). The hydrolysis rate of PDMS is controlled by soil moisture, where the hydrolysis takes place more rapidly with lower moisture content, or when the weather is hot and dry (Lehmann et al., 1998). DMSD can further biodegrade to silicic acid $\left[\mathrm{Si}(\mathrm{OH})_{4}\right]$, due to the oxidation of the methyl groups of DMSD (Stevens, 1998), or can be released into the atmosphere since DMSD is relatively volatile (Lehmann and Miller, 1996).

\subsection{Diffuse emissions from fabrics with hydrocarbon DWR finish}

Hydrocarbon based repellents based on paraffin waxes (Marino, 1998), or DWRs based on fatty acid side chains (Lalman and Bagley, 2001), will have similar mechanisms of polymer degradation through photo-oxidation and hydrolysis as previously discussed for side-chain fluorinated polymer DWR technologies. In contrast to side-chain fluorinated polymer DWR products, hydrocarbon DWRs have a high chance of complete biodegradation over time (Archroma, 2014). However, the degradation pathways of state-of-the-art hydrocarbon DWRs are not fully understood and further investigations are required to obtain knowledge about their relevancy as a mechanism of release of environmental pollutants.

\subsection{Diffuse emissions from fabrics with other DWR finishes}

Dendrimers are largely hydrocarbon based structures which would, similarly to hydrocarbon-based DWRs, be degradable in principle. The surface modifications of dendrimer DWRs, however, will influence the loss of chemicals and the degradation rates; e.g. if the surfaces are modified with perfluoroalkyl chains dendrimer DWRs could release these 
persistent substances to the environment. According to the manufactures dendrimer based DWRs are not expected to contain (Möller, 2009) or release nanoparticles to the environment. Fabrics containing inorganic nanoparticle based DWRs will presumably release inorganic nanoparticles to the environment as a result of abrasion ( $\mathrm{Su}$ and $\mathrm{Li}$, 2010). There are no published studies on the loss of chemicals or particles from dendrimer or inorganic nanoparticle DWRs.

\section{Hazard assessment of diffusively emitted DWR related substances}

To evaluate the potential environmental impact of the release of DWR related substances to the environment during the use-phase of the fabric (as described in the previous section), a hazard assessment was made for selected substances in each of the four groups of DWR chemistry; side-chain fluorinated polymers, silicone and hydrocarbon polymeric DWRs and other chemistries (dendrimers and inorganic nanoparticles). The hazard assessment only includes substances that could be released from the fabric with DWR finish and that are related to the DWR agent. All other substances in the DWR formulations, e.g. cross linkers, metal salts. were excluded (see Section 2.3).

The DWRs based on long-chain per- or polyfluoroalkyl side chains, currently being phased out, was selected as a benchmark due to their agreed technical advantages (Zero Discharge of Hazardous Chemicals (ZDHC), 2012) but at the same time acknowledged hazardous properties (see e.g. Vierke et al. (2012)). The substance selected to represent the benchmark was PFOA, since it is a terminal degradation product of telomer based C8 side-chain fluorinated polymers (i.e. long-chain side-chain fluorinated polymers). Additionally PFOA and PFOA precursors are possible impurities in such DWR formulations. For short-chain side-chain fluorinated polymers PFHxA and PFBS were selected to represent C6 (fluorotelomer based) and C4 (perfluoroalkanesulfonyl fluoride based) technologies, respectively, on the same basis as presented for PFOA above. Other substances relevant as impurities or intermediate degradation products to the side-chain fluorinated polymer DWRs were not considered since these are less relevant for environmental accumulation. For the silicone based DWRs, short-chain silanols (PDMS degradation products with a silicone chain length of two or longer), DMSD and TMS (Graiver et al., 2003), were selected as relevant for the hazard assessment. In addition the cyclic siloxanes D4 and D5 were included since they may remain on the fabric as impurities (see Section 3). For the hydrocarbon-based DWRs, paraffin wax was selected for hazard assessment. Finally, dendrimers and inorganic nanoparticles used in DWR were not sufficiently well described in the available literature for us to be able to define what chemicals structure that provide the water (and oil) repellent function and therefore we could not select substances relevant for hazard assessment. However, functional groups, either hydrocarbon, silicone or PFAS, that could be used also on dendrimers or inorganic nanoparticles are assessed within their respective category. Table 3 shows an overview of the hazard assessment which is further detailed below and in the SM.

PFOA, the benchmark substance, is a persistent, bioaccumulative and toxic (PBT) substance. It is not expected to degrade in aquatic or terrestrial environment under natural conditions, it has been shown to bioaccumulate in mammals and it has high developmental and organ specific toxicity (BAuA, 2013; ECHA, 2011; OECD, 2008; Vierke et al., 2012). Both acute and chronic ecotoxicity is reported to be low when tested over three trophic levels (OECD, 2008) (results from microcosm and mesocosm test (Hanson et al., 2005; Sanderson et al., 2003; Sanderson et al., 2004) do however indicate that ecotoxicity may manifest at lower concentrations, hence the uncertainty of the classification), which is an interesting difference to PFOS, another C8 PFAS, which has been shown to be highly toxic to aquatic wildlife (see e.g. Beach et al. (2006)).

PFHxA and PFBS, representing the alternative side-chain fluorinated polymer DWRs, are equally persistent as the benchmark analogue PFOA (Butt et al., 2014). As for PFOA the bioaccumulation in fish was found to

\section{Table 3}

Hazard assessment for selected DWR related substances that reach the environment via diffuse emissions. Degradation products are denoted \# and impurities are denoted a. Hazard classification abbreviations are: $\mathrm{vL}=$ very low, $\mathrm{L}=$ low, $\mathrm{M}=$ moderate, $\mathrm{H}=$ high, $\mathrm{vH}$ $=$ very high, $\mathrm{PEA}=$ potentially endocrine active, $\mathrm{DG}=$ data gap. Classifications in italics are of low confidence and in bold of high confidence. Classifications based on estimated data are marked with an asterisk $\left({ }^{*}\right)$. Endpoint abbreviations are explained in Table 2 See SM Tables S2-S9 for detailed information on the basis of classification. The paraffin wax classification is based on a GreenScreen report (ToxServices LLC, 2013).

\begin{tabular}{|c|c|c|c|c|c|c|c|c|c|c|c|c|}
\hline \multirow{3}{*}{ Substance } & \multicolumn{12}{|c|}{ Hazard classification per endpoint } \\
\hline & \multicolumn{8}{|c|}{ Human health } & \multicolumn{2}{|c|}{ Ecotox } & \multicolumn{2}{|c|}{ Fate } \\
\hline & C & M & $\mathbf{R}$ & D & $\mathbf{E}$ & AT & ST & $\mathbf{N}$ & AA & CA & $\mathbf{P}$ & B \\
\hline \multicolumn{13}{|c|}{ Benchmark } \\
\hline PFOA\#品 & H & $\mathbf{L}$ & $H$ & H & PEA & $\mathbf{M}$ & H & DG & $\mathbf{L}$ & $L$ & vH & H \\
\hline \multicolumn{13}{|c|}{ Side-chain fluorinated polymers } \\
\hline PFHXA \#a & $L$ & $\mathbf{L}$ & $M$ & $M$ & PEA & $\mathbf{L}$ & $M$ & DG & $L$ & $L$ & vH & $\mathbf{L}$ \\
\hline PFBS \#a & DG & $\mathbf{L}$ & $L$ & $\mathbf{L}$ & PEA & $\mathbf{L}$ & $L$ & DG & $L$ & $L$ & vH & $\mathbf{L}$ \\
\hline \multicolumn{13}{|c|}{ Silicones } \\
\hline Short-chain silanols \# & DG & DG & DG & DG & DG & DG & DG & DG & DG & DG & DG & DG \\
\hline DMSD \# & DG & DG & DG & DG & DG & DG & $M$ & DG & DG & DG & $v H$ & $L^{*}$ \\
\hline TMS \# & DG & $L$ & DG & $L$ & DG & $\mathbf{M}$ & $M$ & DG & $\mathbf{L}$ & DG & DG & $L^{*}$ \\
\hline D4 a & $\mathbf{L}$ & $L$ & $L$ & $\mathbf{L}$ & PEA & $\mathbf{L}$ & $\mathbf{H}$ & DG & $L$ & vH & $\mathrm{vH}$ & $v H$ \\
\hline D5 a & $\mathbf{L}$ & $\mathbf{L}$ & $\mathbf{L}$ & $\mathbf{L}$ & PEA & $H$ & $\mathrm{H}$ & DG & $\mathbf{L}$ & $L$ & $\mathrm{vH}$ & $v H$ \\
\hline \multicolumn{13}{|c|}{ Hydrocarbons } \\
\hline Paraffin Wax \# & $\mathbf{L}$ & $\mathbf{L}$ & $v L^{*}$ & $v L^{*}$ & DG & $\mathbf{L}$ & $M$ & DG & $L^{*}$ & $L^{*}$ & $\mathbf{L}$ & $L^{*}$ \\
\hline \multicolumn{13}{|c|}{ Other chemistries (dendrimers, inorg. nano particles) } \\
\hline Unknown & DG & DG & DG & DG & DG & DG & DG & DG & DG & DG & DG & DG \\
\hline
\end{tabular}

be low (Falk et al., 2015; Goeritz et al., 2013; Martin et al., 2003a,b; NICNAS, 2005) and levels in humans and terrestrial wildlife were also low (in comparison to levels of long-chain PFAS), or not detectable (Bytingsvik et al., 2012; ENVIRON International Corporation, 2014; Falandysz et al., 2006; Leat et al., 2013; Loi et al., 2011; Olsen et al., 2009; Persson et al., 2013; Russell et al., 2013; Taniyasu et al., 2003, 2013; Thompson et al., 2011; Van De Vijver et al., 2005; Vicente et al., 2015; Yamada et al., 2014). Field based BCF values are indicated to be higher than those determined in the laboratory, but still below 500 (Hong et al., 2014; Kwadijk et al., 2010; Naile et al., 2013). These substances were thus classified to have low bioaccumulation potential due to the higher elimination rate of the short-chain PFAAs in comparison to PFOA (Russell et al., 2013). Despite some field based BCF values exceeding 100 , the weight of evidence allowed for a high confidence score of the classification. PFHxA but not PFBS has been shown to be toxic to reproduction and development in mammals, albeit at higher concentrations than PFOA (Hoberman A. M. (Charles River Laboratories), 2011a,b; Iwai and Hoberman, 2014; Lieder et al., 2009; Loveless et al., 2009; NICNAS, 2005). PFHxA was classified as moderately hazardous in three human health categories while PFBS was only classified as being of low hazard in the same categories. It is uncertain if the difference in hazard profile between PFHxA and PFBS is due to actual differences or differences in the types of test results available. It should also be noted that the PFAAs have very different serum elimination half-lives in different mammals, including humans (Chengelis et al., 2009; Olsen et al., 2009; Wambaugh et al., 2013), and for risk assessment the recommendation is to base the assessment on internal dose metrics rather than external, to avoid underestimation of the risks to humans (Butenhoff and Rodricks, 2015), but no such attempts were done within this review. PFHxA and PFBS, like PFOA, have been shown to have a low aquatic toxicity both at acute and chronic exposure in standardised tests (Barmentlo et al., 2014; Burke J. (Covance Laboratories Ltd) and Scholey A. (Covance Laboratories Ltd), 2008; ENVIRON International Corporation, 2014; Hoke R. A. (E.I. du Pont de Nemours and Company), 2009a,b,c); Latala et al., 2009; Liu et al., 2008). Results from non-standard tests do however indicate that these 
substances may exert negative effects in the aquatic environment at concentrations below the criteria for low hazard (Lou et al., 2013; Wang et al., 2014).

For the short-chain silanols, DMSD and TMS the hazard assessment contains many data gaps, which renders comparison to PFOA, the benchmark, difficult. Still, it is apparent that these substances do have hazard characteristics of concern as they are classified as hazardous in both toxicity and fate categories. Additionally, D4 and D5 though presumably present in low concentrations, have several characteristics of concern in both toxicity and fate categories. Despite the equal hazard classification for persistence between DMSD, D4 and D5 and the PFASs there is an important difference between the compounds. While the PFAS do not degrade at all in water or soil, and only extremely slowly in air (half-life 130 days (OECD, 2008)), siloxanes do degrade in the environment (Graiver et al., 2003), albeit slow enough to be classified as persistent. Furthermore, the siloxanes will be removed from the water column in the aquatic compartment, where hazards are indicated to be high (D4), and either evaporate and degrade in air by reaction with hydroxyl radicals (Brooke et al., 2009a,b; Graiver et al., 2003) or partition strongly to the sediments (Brooke et al., 2009a,b). Whether such fate processes ameliorates the risks was not assessed within this review. Additionally, siloxanes can bioaccumulate in aquatic food webs because they can be taken up by benthic invertebrates at lower trophic levels (Borgå et al., 2013; D.G. Wang et al., 2013).

For the hydrocarbon based DWRs, paraffin wax emerges as a low hazard substance in comparison with the benchmark PFOA. It was assessed by ToxServices LLC (2013) and found to be GreenScreen Benchmark 3, i.e. recommended for use but there are still opportunities for improvement according to the method (hazard classification reproduced in Table 3 ).

Since dendrimers or inorganic nanoparticles were not sufficiently well described in the available literature for us to be able to select substances for hazard assessment, hazard profiles could not be prepared.

\section{Discussion and outlook}

A number of DWR technologies are available on the market today, and in this review we describe how they could be categorised as sidechain fluorinated polymers, silicones and hydrocarbon based polymers and other chemistries (dendrimers and inorganic nanoparticles). The polymer based DWRs are based on the same structural principles, but the DWR chemistry employed has important implications for repellency of liquids. The side-chain fluorinated polymer DWRs, based on per- and polyfluoroalkyl side chains $\left[-\left(\mathrm{CF}_{2}\right)_{n}-\mathrm{CF}_{3}\right.$ or $\left.-\left(\mathrm{CH}_{2}\right)_{\mathrm{m}}-\left(\mathrm{CF}_{2}\right)_{n}-\mathrm{CF}_{3}\right]$, are the most effective water repellent finishes for textiles and are unique in that they can additionally deliver lipo- or oleophobic properties. Oil/stain repellency is a key property for stain resistant finishes and especially important for textiles that have to withstand the penetration of harmful liquids. The silicone based polymeric DWRs, based on the PDMS backbone [- $\left.\mathrm{Si}\left(\mathrm{CH}_{3}\right)_{2} \mathrm{O}-\right]$, have high water repellency and in addition to the hydrophobic character of the PDMS chain, fabrics treated with these types of DWR polymers result in finishes with a soft feel to the hand. The hydrocarbon based polymeric DWRs, based on crystallised linear nalkyl chains $\left[-\left(\mathrm{CH}_{2}\right)_{n}-\mathrm{CH}_{3}\right]$, resemble the natural low energy surfaces of plant leaves (Barthlott and Neinhuis, 1997; Koch and Ensikat, 2008) that develop repellency with crystalline wax tubules (Dora and Wandelt, 2011). Physically bound waxes had poor durability during laundering or dry cleaning (Kissa, 2001), which has led to the development of more stable DWRs like melamine-based resins. DWRs based on dendrimers and nanoparticles mimic the repellent nanostructures of lotus plant leaves and can be modified with fatty acids, per- or polyfluoroalkyl groups or polyalkylsiloxanes to achieve repellent properties.

New DWR technologies are continuously being developed due to policy requirements and consumer demands. With the aim to improve environmental and health characteristics of the DWR agents the long-chain side-chain fluorinated polymers are being phased out and some manufacturers of textile products finished with DWR have phased out PFASs completely. These changes are happening with a remarkable speed. In this review DWRs available on the market by the time of the literature review, i.e. January 2015, have been described and DWRs marketed later are not included. However, since all DWRs are based on comparable structural elements regarding their functionality within the textile, the principles of the four major groups of DWRs we describe, the side-chain fluorinated polymers, silicones and hydrocarbon based polymers, and nanotechnologies and dendrimers, will be applicable to many of the new systems.

The phase-out of PFASs in many types of products is in line with our assessment, showing that PFASs have hazard properties of concern, particularly their environmental persistence. Our assessment shows that the hazard profiles belonging to the three groups of polymeric DWR substitutes (short-chain side-chain fluorinated polymers, silicones and hydrocarbon based polymers) are indeed improved in comparison to the benchmark long-chain side-chain fluorinated polymer DWRs. Despite this, none of the assessed substances are completely free from concern. Although the short-chain PFASs (related to the short-chain sidechain fluorinated polymer DWRs) are less bioaccumulative than their long-chain analogues, their equally and exceptionally high persistence is a motivation to limit the release of these substances to the environment. Release of highly persistent chemicals such as PFASs into the environment will result in poorly reversible exposures on local (e.g. contaminated groundwater) and planetary scales (MacLeod et al., 2014). If PFAS use and release continues, levels and thus exposures will increase over time in some parts of the environment and effect thresholds will ultimately be breached. Substances related to the silicone DWRs were classified with high hazard in human health, ecotoxicity and fate endpoints. In this sense they seem almost as hazardous as the long-chain PFASs. However, in comparison to the PFASs they are les persistent and studies of the environmental fate of these substances indicate that the actual risks associated with their release may be reduced due to their partitioning to air where they are eventually removed by reaction with hydroxyl radicals (Graiver et al., 2003). The hydrocarbons, as represented by paraffin wax, have the most favourable hazard profile. It is noteworthy that the group of other chemistries are currently gaining market shares despite the large data gaps on possible hazards connected to their use. Expanding the scope to not only cover the hydrophobic moiety of the chemical structure of the DWR agent we find that toxicity tests on polyaminoamine (PAMAM) dendrimers reveal that these kinds of substances are not completely free of hazard concerns (Blaise et al., 2014; Oliveira et al., 2014; Shahbazi et al., 2015; Suarez et al., 2011) and also inorganic nanoparticles has raised concerns in other contexts (Oberdörster et al., 2007).

Given that some of the substances associated with hazard characteristics of concern are relevant due to their presence as impurities in the DWR formulations, risks associated with their release could be reduced if the presence of impurities is reduced in the manufacture of the DWR. The manufacturing industry is improving processes to reduce or eliminate PFCA and FTOH in its formulations (Daikin, 2016; Reisch, 2011; Rudolf Group, 2016; US EPA, 2013, 2014). Similar actions have been taken for the silicone based DWRs and were mentioned already in 2011 (Reisch, 2011). Further actions to reduce residual content to minimum levels are of course desirable from an environmental perspective. One may argue that for some of these substances, e.g. the cyclic siloxanes D4 and D5, fabrics with DWR finish are a small source compared to the environmental release from other uses of silicones. Nevertheless, releases of substances with such severe hazard profiles (identified as POP, i.e. meeting Stockholm Convention Annex D criteria (UNEP, 2014)) should be minimised wherever possible.

The risks associated with the diffuse emissions of DWR related substances during the fabric use phase depend on the quantity emitted and the fate of the substance, i.e. the exposure. However, reducing emissions of hazardous substances whenever possible is advisable since that will 


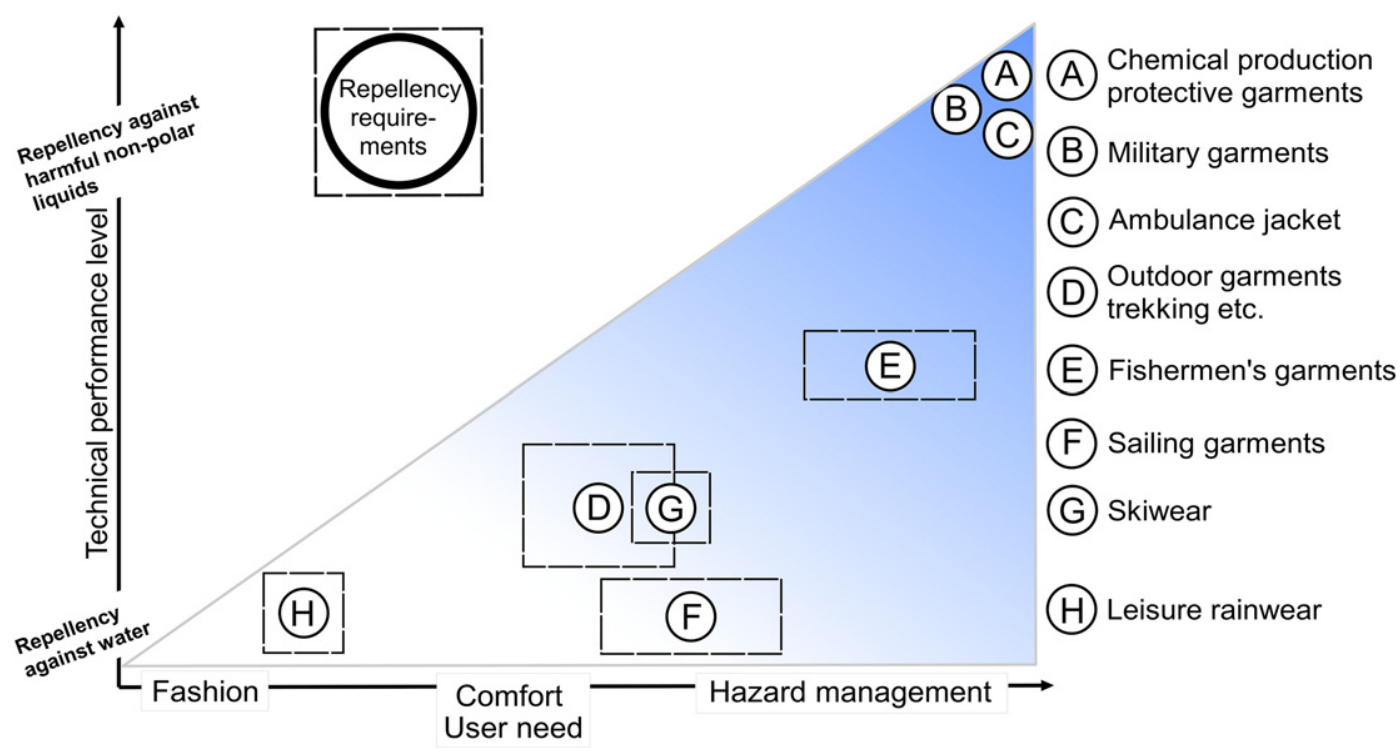

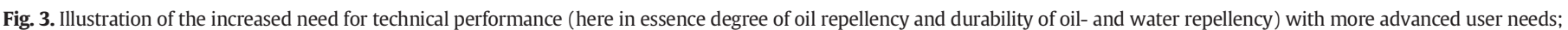

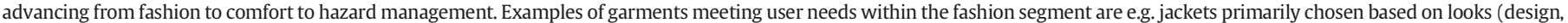

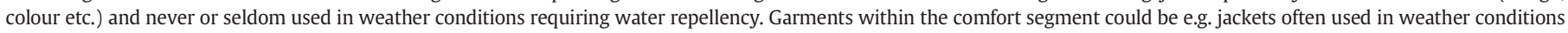

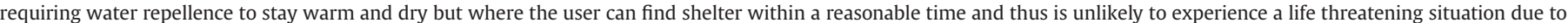

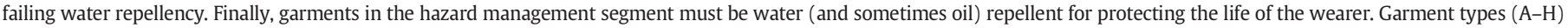
were subjectively placed in the graph and further work is needed to quantify the metrics on the graph's axes.

reduce the potential risks, irrespective of exposure. To reduce the environmental impact of the diffuse emissions from the fabrics with DWR finish a way forward is to carefully weigh performance requirements with hazard properties when selecting DWR. Fig. 3 illustrates how DWR applications (garment types) need to meet different user needs and fulfil certain technical performance criteria. In the case of protective clothing repellent properties provided by DWRs can be a matter of life protection and to this date only fluorinated materials might achieve certain criteria. This could be seen in contrast to products where the DWR finish is more a question of comfort and a good water repellence might be feasible with non-fluorinated DWRs. Between these two contrasting examples lies a grey-scale where certain outdoor activities may require high performance garments in order to protect the wearer of potential life threatening situations. Relevant in this context are also the discussions regarding possible discrepancies between the technical performance criteria set up by the manufacturers of DWR formulations as well as water repellent textile and garments and the actual needs of the consumers. Indications that consumers' and brands' expectations on the garment may differ was found in a questionnaire study (Burman, 2014).

This critical review highlights the data gaps in the currently available literature, both regarding the specifications of the DWR technologies on the market, which are of course often trade secrets, and data on diffuse emissions and hazard characteristics. Further research is called for to fill the data gaps we have identified, both regarding the hazard profiles and releases of relevant substances. Without such data the manufacturers of products with DWR finish, and consumers, cannot make fully informed choices when selecting textile products with DWR finish.

In our on-going research to assess the human and environmental risk connected to the DWRs we aim to confirm the relevancy of loss mechanisms (see Figs. 2 and S7 in SM) in practical experiments. The data generated will support a life cycle assessment (LCA) to estimate long-term advantages and disadvantages of the different DWR technologies.

To conclude we would like to highlight that DWRs currently on the market need to be further improved to achieve hazard profiles that do not cause concerns with regards to the environmental risks. Based on our hazard and property assessment of DWRs, side-chain fluorinated polymer DWRs should only be used in applications where oil/stain repellency is essential. Otherwise the non-fluorinated DWRs, especially hydrocarbon DWRs, are preferable for everyday uses where water repellency alone is required because they are relatively less hazardous. Silicone DWRs could be made less hazardous if residual levels of cyclic methyl siloxanes could be reduced further. Until environmentally improved DWRs are available on the market, we recommend manufacturers of water repellent garments to carefully consider their choice of DWR, based on the overview provided here, with the aim to minimise release of hazardous substances.

\section{Conflict of interest disclosure}

The authors do not have conflicts of interest to report.

\section{Acknowledgements}

This research was funded by the Swedish Research Council for Environment, Agricultural Sciences and Spatial Planning (FORMAS) under grant agreement no. 2012-2148 (Project SUPFES). The aim of project SUPFES (www.supfes.eu) is to help industry find alternatives that can replace fluorinated chemicals which are harmful to the environment. This is done by assessing the characteristics of the fluorinated chemicals and assessing the performance and environmental impact from alternatives. The results presented in the present article stem from early work in the project, this work will be followed by technical performance testing, emission studies, life cycle assessments etc.

We thank our colleagues and project partners at Swerea IVF (present and previous) who have provided us valuable input during the work with this manuscript. We also thank the representatives from the major raw material producers who kindly provided us with information in interview sessions.

\section{Appendix A. Supplementary data}

Supplementary data to this article can be found online at http://dx. doi.org/10.1016/j.envint.2016.02.035. 


\section{References}

3M, 2013. MSDS Scotchgard TM Outdoor Water Shield; Scotchguard TM (Cat. No. 5020, 5019) (US).

Abdullah, I., Blackburn, R.S., Russell, S.J., Taylor, J., 2006. Abrasion phenomena in twill tencel fabric. J. Appl. Polym. Sci. 102, 1391-1398.

Archroma, 2014. Safety Data Arkophob FFR, Biodegradability After OECD Test Guideline 302B.

Arunyadej, S., Mitchell, R., Walton, J., Carr, C.M., 1998. An investigation into the effect of laundering on the repellency behaviour of a fluorochemical-treated cotton fabric. J. Text. Inst. 89, 696-702.

Barmentlo, S.H., Stel, J.M., van Doorn, M., Eschauzier, C., de Voogt, P., Kraak, M.H., 2014. Acute and chronic toxicity of short chained perfluoroalkyl substances to Daphnia magna. Environ. Pollut. 198C, 47-53.

Barthlott, W., Neinhuis, C., 1997. Purity of the sacred lotus, or escape from contamination in biological surfaces. Planta 202, 1-8.

Batsanov, S.S., 2001. Van der Waals radii of elements. Inorg. Mater. 37, 871-885.

BAuA, 2013. Annex XV Dossier. Proposal for Identification of a Substance as a CMR $1 \mathrm{a}$ or $1 \mathrm{~b}, \mathrm{Pbt}, \mathrm{vPvB}$ or a Substance of an Equivalent Level of Concern. Pentadecafluorooctanoic Acid (PFOA) (Dortmund, Germany).

Beach, S.A., Newsted, J.L., Coady, K., Giesy, J.P., 2006. Ecotoxicological Evaluation of Perfluorooctanesulfonate (PFOS). In: Ware, G.W. (Ed.)Reviews of Environmental Contamination and Toxicology vol. 186.

Benzema, 2015. ECOPERL ACTIVE: hydrophobierung/oleophobierung basierend auf speziellen funktionalisierten polymeren/wachsen. http://www.rudolf-duraner. com.tr/en/products/product-brochures-archive/details/brochure/ruco-1514-112013.html.

Berger, U., Herzke, D., 2006. Per- and polyfluorinated alkyl substances (PFAS) extracted from textile samples. Organohalogen Compd. 68, 2023-2026.

Blaise, C., Gagné, F., Auclair, J., Maysinger, D., Sutthivaiyakit, P., 2014. Ecotoxicity of a potential drug nano-formulation: PAMAM-dendrimer and minocycline. J. Xenobiotics 4.

Bluesign, 2012. Management of Per- and Polyfluoroalkyl Substances (PFASs) According to Bluesign ${ }^{\circ}$ Criteria. Fact Sheet | PFAS Management | November 2012.

Borgå, K., Fjeld, E., Kierkegaard, A., McLachlan, M.S., 2013. Consistency in trophic magnification factors of cyclic methyl siloxanes in pelagic freshwater food webs leading to brown trout. Environ. Sci. Technol. 47, 14394-14402.

Bresee, R.R., 1986. General effects of ageing on textiles. J. Am. Inst. Conserv. 25, 39-48.

Brooke, D.N., Crookes, M.J., Gray, D., Robertson, S., 2009a. Environmental Risk Assessment Report: Decamethylcyclopentasiloxane. Environment Agency, Rio House, Waterside Drive, Aztec West, Almondsbury, Bristol, BS32 4UD.

Brooke, D.N., Crookes, M.J., Gray, D., Robertson, S., 2009b. Environmental Risk Assessment Report: Octamethylcyclotetrasiloxane. Environment Agency, Rio House, Waterside Drive, Aztec West, Almondsbury, Bristol, BS32 4UD.

Browne, M.A., Crump, P., Niven, S.J., Teuten, E., Tonkin, A., Galloway, T., Thompson, R., 2011. Accumulation of microplastic on shorelines woldwide: sources and sinks. Environ. Sci. Technol. 45, 9175-9179.

Buck, R.C., Franklin, J., Berger, U., Conder, J.M., Cousins, I.T., de Voogt, P., Jensen, A.A., Kannan, K., Mabury, S.A., van Leeuwen, S.P., 2011. Perfluoroalkyl and polyfluoroalkyl substances in the environment: terminology, classification, and origins. Integr. Environ. Assess. Manag. 7, 513-541.

Burke, J. (Covance Laboratories Ltd); Scholey A. (Covance Laboratories Ltd). PFH Ammonium Salt: Fish, Early Life Stage Toxicity Test to Oncorhynchus mykiss (Rainbow Trout). Sponsor: Daikin Industries, LTD. North Yorkshire, UK; 2008.

Burman, G., 2014. Expectations of Durable Water Repellent Fabric Finishes. An Account of the Project Work Carried Out for the Degree of BSc (Hon's) Retail Buying (Textiles). De Montfort University, Leicester, UK.

Butenhoff, J.L., Rodricks, J.V., 2015. Human Health Risk Assessment of Perfluoroalkyl Acids. In: DeWitt, J.C. (Ed.), Toxicological Effects of Perfluoroalkyl and Polyfluoroalkyl Substances.

Butt, C.M., Muir, D.C.G., Mabury, S.A., 2014. Biotransformation pathways of fluorotelomerbased polyfluoroalkyl substances: a review. Environ. Toxicol. Chem. 33, 243-267.

Bytingsvik, J., van Leeuwen, S.P.J., Hamers, T., Swart, K., Aars, J., Lie, E., Nilsen, E.M.E., Wiig, T., Derocher, A.E., Jenssen, B.M., 2012. Perfluoroalkyl substances in polar bear mother-cub pairs: a comparative study based on plasma levels from 1998 and 2008. Environ. Int. 49, 92-99.

Casper, P.M.-K.C., 2014. Renewable Textile Finishing in the Context of Textile Reprocessing 8 Aachen-Dresden International Textile Conference (Dreseden).

Castelvetro, V., Aglietto, M., Ciardelli, F., Chiantore, O., Lazzari, M., Toniolo, L., 2002. Structure control, coating properties, and durability of fluorinated acrylic-based polymers. J. Coatings Technol. 74, 57-66.

Chemie, K., 2015a. Data sheet KAPPAPHOB RIW 6: speziell zur Reimprägnierung von wetterschutzbekleidung entwickelte fluorcarbonpolymer-emulsion (C 6). http://www.kapp-chemie.de/176.php.

Chemie, R., 2015b. RUCO 1514: intelligente selbstorganisation für beste wasserabweisung fluorfrei. http://www.rudolf-duraner.com.tr/en/products/product-brochures-archive/ details/brochure/ruco-1514-11-2013.html.

Chengelis, C.P., Kirkpatrick, J.B., Myers, N.R., Shinohara, M., Stetson, P.L., Sved, D.W., 2009 Comparison of the toxicokinetic behavior of perfluorohexanoic acid (PFHxA) and nonafluorobutane-1-sulfonic acid (PFBS) in cynomolgus monkeys and rats. Reprod. Toxicol. 27, 400-406.

Chiellini, E., Solaro, R., 2003. Biodegradable Polymers and Plastics: Springer Science \& Business Media.

Clean Production Action, 2013. GreenScreen ${ }^{\circledR}$ chemical hazard assessment procedure V1.2 final. http://www.greenscreenchemicals.org/info/guidance-and-methoddocuments-downloads;
Clean Production Action, 2014. GreenScreen ${ }^{\circledR}$ hazard criteria. http://www greenscreenchemicals.org/info/guidance-and-method-documents-downloads: GreenScreen ${ }^{\circ}$.

Daikin, 2016. Product grade and features. https://www.daikin.com/chm/products/fiber/ index.html;

Dechant, J., 1985. Handbook of fiber science and technology. Vol. II. Chemical processing of fibers and fabrics. Functional finishes: part B. Hg. von Menachem Lewin und Stephen B. Sello. New York/Basel: Marcel Dekker, Inc. 1984. ISBN 0-8247-7118-4. XX, 515S., geb. SFr. 283.-. Acta Polym. 36242.

Dinglasan-Panlilio, M.J.A., Mabury, S.A., 2006. Significant residual fluorinated alcohols present in various fluorinated materials. Environ. Sci. Technol. 40, 1447-1453.

Dora, S.K., Wandelt, K., 2011. Recrystallization of tubules from natural lotus (Nelumbo nucifera) wax on a $\mathrm{Au}(111)$ surface. Beilstein J. Nanotechnol. 2, 261-267.

Dreyer, A., Neugebauer, F., Neuhaus, T., Selke, S., 2014. Emission of Perfluoroalkyl Substances (PFASs) From Textiles. Dioxin 2014 (Madrid).

ECHA, 2011. Committee for Risk Assessment RAC Opinion Proposing Harmonised Classification and Labelling at Community Level of Perfluorooctanoic Acid (PFOA) (Helsinki, Finland).

ECHA, 2014a. Candidate list of substances of very high concern for authorisation. http:// echa.europa.eu/web/guest/candidate-list-table;

ECHA, 2014b. Submitted restriction proposals perfluorooctanoic acid. http://echa.europa.eu/ registry-of-submitted-restriction-proposal-intentions/-/substance-rev/1841/term;.

ENVIRON International Corporation, 2014. Assessment of POP Criteria for Specific Short-Chain Perfluorinated Alkyl Substances Prepared for: FluoroCouncil, Arlington, Virginia, USA.

Esumi, K., Ueno, M., 2003. Structure-Performance Relationships in Surfactants. CRC Press.

Falandysz, J., Taniyasu, S., Gulkowska, A., Yamashita, N., Schulte-Oehlmann, U., 2006. Is fish a major source of fluoridated surfactants and repellents in humans living on the baltic coast? Environ. Sci. Technol. 40, 748-751.

Falk, S., Failing, K., Georgii, S., Brunn, H., Stahl, T., 2015. Tissue specific uptake and elimination of perfluoroalkyl acids (PFAAs) in adult rainbow trout (Oncorhynchus mykiss) after dietary exposure. Chemosphere. 129, 150-156.

Feng, S., Poss, A.J., Singh, R.R., Lin, Y., 2014. Water and Oil-Repellent Fluoropolymer Having a Short Perfluorinated Chain (Google Patents).

Filipovic, M., Berger, U., McLachlan, M.S., 2013. Mass balance of perfluoroalkyl acids in the Baltic Sea. Environ. Sci. Technol. 4088-4095.

Fournier, J.A., Phan, C.L., Bohn, R.K., 2011. Microwave spectroscopy and characterization of the helical conformer of perfluorohexane. ARKIVOC $5,11$.

Fox, H.W., Zisman, W.A., 1950. The spreading of liquids on low energy surfaces. I. polytetrafluoroethylene. J. Colloid Sci. 5, 514-531.

Franchina, J.G., 2002. High-Durability, Low-Yellowing Repellent for Textiles (Google Patents).

Freeston, W.D., 1981. Chemical Protective Clothing Systems [ABMPS Report No. 140]. National Academy Press.

Frolov, Y.L., Voronkov, M.G., Strashnikova, N.V., Shergina, N.I., 1992. Hydrogen bonding involving the siloxane group. J. Mol. Struct. 270, 205-215.

Frömel, T., Knepper, T.P., 2010. Biodegradation of Fluorinated Alkyl Substances. Reviews of Environmental Contamination and Toxicology vol. 208. Springer.

Fuchs, A., Artner, W., Zwikirsch, B., 2010. Flourine-Free Aqueous Dispersion for Treating Textile Fabrics (Google Patents).

Gibson, P., 2008. Water-repellent treatment on military uniform fabrics: physiological and comfort implications. J. Ind. Text. 38, 43-54.

Goeritz, I., Falk, S., Stahl, T., Schäfers, C., Schlechtriem, C., 2013. Biomagnification and tissue distribution of perfluoroalkyl substances (PFASs) in market-size rainbow trout (Oncorhynchus mykiss). Environ. Toxicol. Chem. 32, 2078-2088.

Gomis, M.I., Wang, Z., Scheringer, M., Cousins, I.T., 2015. A modeling assessment of the physicochemical properties and environmental fate of emerging and novel per- and polyfluoroalkyl substances. Sci. Total Environ. 505, 981-991.

Graiver, D., Farminer, K.W., Narayan, R., 2003. A review of the fate and effects of silicones in the environment. J. Polym. Environ. 11, 129-136.

Greenberg, S.A., Alfrey, T., 1954. Side chain crystallization of n-alkyl polymethacrylates and polyacrylates1. J. Am. Chem. Soc. 76, 6280-6285.

Hanson, M.L., Small, J., Sibley, P.K., Boudreau, T.M., Brain, R.A., Mabury, S.A., Solomon, K.R., 2005. Microcosm evaluation of the fate, toxicity, and risk to aquatic macrophytes from perfluorooctanoic acid (PFOA). Arch. Environ. Contam. Toxicol. 49, 307-316.

Hanssen, L., Herzke, D., 2014. Investigation of Outdoor Textiles With Respect to Determine the Content of Ionic Perfluorinated Substances (PFASs). Evaluation of End Results. NILU (Norwegian Institute for Air Research) (http://www.miljodirektoratet. no/Documents/publikasjoner/M306/M306.pdf).

Hegemann, D., 2005. Stain repellent finishing on fabrics. Adv. Eng. Mater. 7, 401-404.

Herzke, D., Olsson, E., Posner, S., 2012. Perfluoroalkyl and polyfluoroalkyl substances (PFASs) in consumer products in Norway - a pilot study. Chemosphere 88, 980-987.

Hoberman, A.M. (Charles River Laboratories). FINAL REPORT. Oral (Gavage) Combined Developmental and Perinatal/Postnatal Reproduction Toxicity Study of PFH Ammonium Salt (Ammonium salt of Perfluorinated Hexanoic Acid) in Mice (1). Sponsor: Daikin Industries, LTD. in: Charles River Laboratories, ed. Horsham, USA; 2011 a.

Hoberman, A.M. (Charles River Laboratories). FINAL REPORT. Oral (Gavage) Combined Developmental and Perinatal/Postnatal Reproduction Toxicity Study of PFH Ammonium Salt (Ammonium salt of Perfluorinated Hexanoic Acid) in Mice (2). Sponsor: Daikin Industries, LTD. in: Charles River Laboratories, ed. Horsham, USA; 2011b.

Hoke, R.A. (E.I. du Pont de Nemours and Company). H-27579: Static, 72-Hour Growth Inhibition Toxicity Screening Test to the Green Algae, Pseudokirchneriella subcapitata. Newark, Delaware, USA; 2009a.

Hoke, R.A. (E.I. du Pont de Nemours and Company). H-27579: Static, Acute, 48-Hour Toxicity Screening Test with Daphnia magna. Newark, Delaware, USA; 2009b. 
Hoke, R.A. (E.I. du Pont de Nemours and Company). H-27579: Static, Acute, 96-Hour Toxicity Screening Test with Pimephales promelas. Newark, Delaware, USA; 2009c.

Honda, K., Morita, M., Otsuka, H., Takahara, A., 2005. Molecular aggregation structure and surface properties of poly(fluoroalkyl acrylate) thin films. Macromolecules 38, 5699-5705.

Hong, S., Khim, J.S., Wang, T., Naile, J.E., Park, J., Kwon, B.O., Song, S.J., Ryu, J., Codling, G., Jones, P.D., Lu, Y., Giesy, J.P., 2014. Bioaccumulation characteristics of perfluoroalky acids (PFAAs) in coastal organisms from the west coast of South Korea. Chemosphere.

Hu, J., 2008. Fabric Testing: Elsevier

Hu, J., Nie, K., Meng, Q., Zheng, G., 2007. Multifunction Finishing Liquids Containing Dendrimers and the Application of the Liquids in Textile Finishing.

Iverson, I.K., Rudat, M.A., 2010. Soil Repellency Aqueous Dispersions, Soil Repellant Soft Articles, and Methods of Making the Same (Google Patents).

Iwai, H., Hoberman, A.M., 2014. Oral (gavage) combined developmental and perinatal/ postnatal reproduction toxicity study of ammonium salt of perfluorinated hexanoic acid in mice. Int. J. Toxicol. 33, 219-237.

Jones, R.G., 1995. Silicon-Containing Polymers. Royal Society of Chemistry, Cambridge.

Kawai, F., 1995. Breakdown of Plastics and Polymers by Microorganisms. Microbial and Eznymatic Bioproducts. Springer, Berlin Heidelberg.

Kissa, E., 2001. Fluorinated Surfactants and Repellents. CRC Press.

Klima- og miljødepartementet, 2014. In: miljødepartementet K.-o. (Ed.), Forskrift om begrensning i bruk av helse- og miljøfarlige kjemikalier og andre produkter (produktforskriften). Klima- og Miljødepartementet, Norway.

Knepper, T.P., Frömel, T., Gremmel, C., Driezum, I.v., Weil, H., Vestergren, R., Cousins, I. UMWELTBUNDESAMT (UBA), 2014. Understanding the Exposure Pathways of Perand Polyfluoralkyl Substances (PFASs) via Use of PFASs-Containing Products - Risk Estimation for Man and Environment. UMWELTBUNDESAMT (UBA), Dessau-Roßlau (http://www.umweltbundesamt.de/publikationen/understanding-the-exposurepathways-of-per)

Koch, K., Ensikat, H.-J., 2008. The hydrophobic coatings of plant surfaces: epicuticular wax crystals and their morphologies, crystallinity and molecular self-assembly. Micron 39 759-772.

Kwadijk, C., Korytar, P., Koelmans, A.A., 2010. Distribution of perfluorinated compounds in aquatic systems in The Netherlands. Environ. Sci. Technol. 44, 3746-3751.

Lalman, J.A., Bagley, D.M., 2001. Anaerobic degradation and methanogenic inhibitory effects of oleic and stearic acids. Water Res. 35, 2975-2983.

Lang, G.A., 2015. Interview by Steffen Schellenberger

Lassen, C., Jensen, A.A., Warming, M., 2015. Alternatives to perfluoroalkyl and polyfluoroalkyl substances (PFAS) in textiles. Report by COWI A/S and NIPSECT, Comissioned by Danish Ministry of the Environment and Danish EPA.; Survey of Chemical Substances in Consumer Products, No. 137.

Latala, A., Nedzi, M., Stepnowski, P., 2009. Acute toxicity assessment of perfluorinated carboxylic acids towards the Baltic microalgae. Environ. Toxicol. Pharmacol. 28, 167-171.

Leat, E.H.K., Bourgeon, S., Eze, J.I., Muir, D.C.G., Williamson, M., Bustnes, J.O., Furness, R.W. Borga, K., 2013. Perfluoroalkyl substances in eggs and plasma of an avian top predator, great skua (Stercorarius skua), in the North Atlantic. Environ. Toxicol. Chem. 32, 569-576.

Lehmann, R.G., Miller, J.R., 1996. Volatilization and sorption of dimethylsilanediol in soil Environ. Toxicol. Chem. 15, 1455-1460.

Lehmann, R.G., Miller, J.R., Xu, S., Singh, U.B., Reece, C.F., 1998. Degradation of silicone polymer at different soil moistures. Environ. Sci. Technol. 32, 1260-1264.

Lehmann, R.G., Miller, J.R., Kozerski, G.E., 2000. Degradation of silicone polymer in a field soil under natural conditions. Chemosphere 41, 743-749.

Lehotkay, T.W.C.A. D4/D5 impurities in silicone based DWRs, personal communication. 2015

Leonas, K.K., 1998. Effect of laundering on the barrier properties of reusable surgical gown fabrics. Am. J. Infect. Control 26, 495-501.

Lieder, P.H., York, R.G., Hakes, D.C., Chang, S.C., Butenhoff, J.L., 2009. A two-generation ora gavage reproduction study with potassium perfluorobutanesulfonate $(K+P F B S)$ in Sprague Dawley rats. Toxicology 259, 33-45.

Liu, J., Mejia Avendaño, S., 2013. Microbial degradation of polyfluoroalkyl chemicals in the environment: a review. Environ. Int. 61, 98-114.

Liu, J., Lee, L.S., Nies, L.F., Nakatsu, C.H., Turco, R.F., 2007. Biotransformation of 8:2 fluorotelomer alcohol in soil and by soil bacteria isolates. Environ. Sci. Technol. 41, 8024-8030.

Liu, W., Chen, S., Quan, X., Jin, Y.H., 2008. Toxic effect of serial perfluorosulfonic and perfluorocarboxylic acids on the membrane system of a freshwater alga measured by flow cytometry. Environ. Toxicol. Chem. 27, 1597-1604.

LJ-specialities, 2015. ITOGUARD NFC90 repellent finish based on a hydrocarbon polymer obtained from botanical extract. http://www.lj-specialities.co.uk.

Loi, E.I.H., Yeung, L.W.Y., Taniyasu, S., Lam, P.K.S., Kannan, K., Yamashita, N., 2011. Trophic magnification of poly- and perfluorinated compounds in a subtropical food web. Environ. Sci. Technol. 45, 5506-5513.

Lou, Q.Q., Zhang, Y.F., Zhou, Z., Shi, Y.L., Ge, Y.N., Ren, D.K., Xu, H.M., Zhao, Y.X. Wei, W.J., Qin, Z.F., 2013. Effects of perfluorooctanesulfonate an perfluorobutanesulfonate on the growth and sexual development of Xenopus laevis. Ecotoxicology 22, 1133-1144.

Loveless, S.E., Slezak, B., Serex, T. Lewis, J., Mukerji, P., O'Connor, J.C., Donner, E.M., Frame, S.R., Korzeniowski, S.H., Buck, R.C., 2009. Toxicological evaluation of sodium perfluorohexanoate. Toxicology 264, 32-44.

Ludemann, S., Bernheim, M., Sandner, B., Rossler, E., Vogel, H.-B., 1991. Oil and WaterRepellent Finishing of Fiber Materials, Modification by Reaction with Polyfunctional Siloxane.

MacLeod, M., Breitholtz, M., Cousins, I.T., De Wit, C.A., Persson, L.M., Rudén, C., McLachlan, M.S., 2014. Identifying chemicals that are planetary boundary threats. Environ. Sci. Technol. 48, 11057-11063.
Maecker, R., 2015a. Momentive: Phone Conference About Functionalised Silicone DWRs.

Maecker, R.M. Silicones Manufacturing Scheme: Stripped-off process to reduce minimise the residual content in silicone based DWR-polymers, provided in personal communication. 2015b.

Marino, F., 1998. Biodegradation of Paraffin Wax. McGill University, Montréal.

Mark, J.E., 2004. Some interesting things about polysiloxanes. Acc. Chem. Res. 37, 946-953.

Martin, J.W., Mabury, S.A., Solomon, K.R., Muir, D.C.G., 2003a. Bioconcentration and tissue distribution of perfluorinated acids in rainbow trout (Oncorhynchus mykiss). Environ. Toxicol. Chem. 22, 196-204.

Martin, J.W., Mabury, S.A., Solomon, K.R., Muir, D.C.G., 2003b. Dietary accumulation of perfluorinated acids in juvenile rainbow trout (Oncorhynchus mykiss). Environ. Toxicol. Chem. 22, 189-195.

Molander, L., Rudén, C., 2012. Narrow-and-sharp or broad-and-blunt - regulations of hazardous chemicals in consumer products in the European Union. Regul. Toxicol. Pharmacol. 62, 523-531.

Möller, M., 2009. Scientific Expertise on the "Characterisation of Active Ingredients in Oil and Soil Repellent Textile Impregnations".

Morent, R., De Geyter, N., Verschuren, J., De Clerck, K., Kiekens, P., Leys, C., 2008. Nonthermal plasma treatment of textiles. Surf. Coat. Technol. 202, 3427-3449.

Mukhopadhyay, A., Midha, V.K., 2008. A review on designing the waterproof breathable fabrics part I: fundamental principles and designing aspects of breathable fabrics. J. Ind. Text. 37, 225-262.

Naile, J.E., Khim, J.S., Hong, S., Park, J., Kwon, B.O., Ryu, J.S., Hwang, J.H., Jones, P.D., Giesy, J.P., 2013. Distributions and bioconcentration characteristics of perfluorinated compounds in environmental samples collected from the west coast of Korea. Chemosphere 90, 387-394.

Namligoz, E.S., Bahtiyari, M.İ., Hosaf, E., Coban, S., 2009. Performance comparison of new (dendrimer, nanoproduct) and conventional water, oil and stain repellents. Fibres Text. East. Eur. 17, 76-81.

NICNAS, 2005. Existing Hazard Chemical Assessment Report. Potassium Perfluorbutane Sulfonate. Australian Government, Department of Health and Ageing, National Industrial Chemicals Notification and Assessment Scheme (NICNAS), Sydney, Australia.

Oberdörster, G., Stone, V., Donaldson, K., 2007. Toxicology of nanoparticles: a historical perspective. Nanotoxicology 1, 2-25.

OECD, 2008. SIDS Initial Assessment Profile, Summary Conclusions of the SIAR. Perfluorooctanoic Acid (PFOA) and Ammonium Perfluorooctanoate (APFO).

OECD, 2013. OECD/UNEP Global PFC Group. Synthesis Paper on Per- and Polyfluorinated Chemicals (PFCs). Environment, Health and Safety, Environment Directorate, OECD, Paris, France.

Oliveira, E., Casado, M., Faria, M., Soares, A.M., Navas, J.M., Barata, C., Pina, B., 2014. Transcriptomic response of zebrafish embryos to polyaminoamine (PAMAM) dendrimers. Nanotoxicology 8 (Suppl. 1), 92-99.

Olsen, G.W., Chang, S.C., Noker, P.E., Gorman, G.S., Ehresman, D.J., Lieder, P.H., Butenhoff, J.L., 2009. A comparison of the pharmacokinetics of perfluorobutanesulfonate (PFBS) in rats, monkeys, and humans. Toxicology 256, 65-74

Özdil, N., Kayseri, G.Ö., Mengüc, G.S., 2012. In: Adamiak, Marcin (Ed.)Analysis of Abrasion Characteristics in Textiles Vol. 119.

Persson, S., Rotander, A., Kärrman, A., van Bavel, B., Magnusson, U., 2013. Perfluoroalkyl acids in subarctic wild male mink (Neovison vison) in relation to age, season and geographical area. Environ. Int. 59, 425-430.

Rankin, K., 2015. Fluorotelomer-Based Acrylate Polymers as an Indirect Source of Perfluoroalkyl Carboxylates PHD thesis, Jan-2015 Department of Chemistry University of Toronto, Toronto.

Rankin, K., Lee, H., Tseng, P.J., Mabury, S.A., 2014. Investigating the biodegradability of a fluorotelomer-based acrylate polymer in a soil-plant microcosm by indirect and direct analysis. Environ. Sci. Technol. 48, 12783-12790.

Reisch, M.S., 2011. Storm Over Silicones. Chem Eng News.

Renner, R., 2006. The long and the short of perfluorinated replacements. Environ. Sci. Technol. 40, 12-13.

Robert, G., 1996. Impregnate Water-Repellent Fluoropolymer one Side of Fabric, Drying, Fixing and Dyeing on Reverse Side (Google Patents).

Robert, E., Stuart, R., 1970. Oil and Water Repellent (Google Patents).

Rudolf Group, 2016. Information on PFOS and PFOA. http://www.rudolf.de/en/ecology/ information-on-pfos-and-pfoa/:

Russell, M.H., 2015. Aerobic degradation of fluorotelomer-based acrylic polymers. Fluoros 2015 (Golden, CO)

Russell, M.H., Berti, W.R., Szostek, B., Buck, R.C., 2008. Investigation of the biodegradation potential of a fluoroacrylate polymer product in aerobic soils. Environ. Sci. Technol. $42,800-807$

Russell, M.H., Berti, W.R., Szostek, B., Wang, N., Buck, R.C., 2010. Evaluation of PFO formation from the biodegradation of a fluorotelomer-based urethane polymer product in aerobic soils. Polym. Degrad. Stab. 95, 79-85.

Russell, M.H., Nilsson, H., Buck, R.C., 2013. Elimination kinetics of perfluorohexanoic acid in humans and comparison with mouse, rat and monkey. Chemosphere 93, $2419-2425$.

Sanderson, H., Boudreau, T.M., Mabury, S.A., Solomon, K.R., 2003. Impact of perfluorooctanoic acid on the structure of the zooplankton community in indoor microcosms. Aquat. Toxicol. 62, 227-234.

Sanderson, H., Boudreau, T.M., Mabury, S.A., Solomon, K.R., 2004. Effects of perfluorooctane sulfonate and perfluorooctanoic acid on the zooplanktonic community. Ecotoxicol. Environ. Saf. 58, 68-76.

Santen, M., Kallee, U., 2012a. Greenpeace, Chemistry for Any Weather - Greenpeace Tests Outdoor Clothes for Perfluorinated Toxins. Greenpeace, Hamburg.

Santen, M., Kallee, U., 2012b. Greenpeace, Per- and Polyfluorinated Chemicals in Textile Products and Ambient Air. Greenpeace, Hamburg (https://www.switchmed.eu/en/ documents/greenpeace_chemistry-any-weather-pfc-textiles-1.pdf). 
Scheirs, J., 1997. Modern Fluoropolymers: High Performance Polymers for Diverse Applications. Wiley.

Scheringer, M., Trier, X., Cousins, I.T., de Voogt, P., Fletcher, T., Wang, Z., Webster, T.F., 2014. Helsingør statement on poly- and perfluorinated alkyl substances (PFASs). Chemosphere 114, 337-339.

Schindler, W.D., Hauser, P.J., 2004. Chemical Finishing of Textiles. Elsevier.

Schlummer, M., Gruber, L., Fiedler, D., Kizlauskas, M., Müller, J., 2013. Detection of fluorotelomer alcohols in indoor environments and their relevance for human exposure. Environ. Int. 57-58, 42-49.

Shahbazi, B., Khodabandeloo, M., Rezaei, M.J., Rouhi, S., Ramazanzadeh, R., Basiri, M.R., 2015. In vivo and in vitro cytotoxicity and mutagenicity considerations of poly (amido amine) dendrimer. J. Rep. Pharm. Sci. 4, 101-110.

Shishoo, R., 2007. Plasma Technologies for Textiles. Elsevier.

Skotheim, T.A., 1997. Handbook of Conducting Polymers. CRC Press.

Speke, R.W., 1954. Variables in padding processes. J. Soc. Dye. Colour. 70, 221-226.

Spori, D.M., Drobek, T., Zürcher, S., Ochsner, M., Sprecher, C., Mühlebach, A., Spencer, N.D. 2008. Beyond the lotus effect: roughness influences on wetting over a wide surfaceenergy range. Langmuir 24, 5411-5417.

Stevens, C., 1998. Environmental degradation pathways for the breakdown of polydimethylsiloxanes. J. Inorg. Biochem. 69, 203-207.

Stockholm Convention, 2014. The New POPs Under the Stockholm Convention.

Stockholm Convention, 2015. Chemicals Proposed for Listing Under the Convention. UNEP.

$\mathrm{Su}, \mathrm{C}$., Li, J., 2010. The friction property of super-hydrophobic cotton textiles. Appl. Surf. Sci. 256, 4220-4225.

Suarez, I., Rosal, R., Rodriguez, A., Ucles, A., Fernandez-Alba, A., Hernando, M., GarcíaCalvo, E., 2011. Chemical and ecotoxicological assessment of poly (amidoamine) dendrimers in the aquatic environment. TrAC Trends Anal. Chem. 30, 492-506.

Sung, L.-P., Vicini, S., Ho, D.L., Hedhli, L., Olmstead, C., Wood, K.A., 2004. Effect of microstructure of fluorinated acrylic coatings on UV degradation testing. Polymer 45 6639-6646.

Tang, W., Huang, Y., Meng, W., Qing, F.-L., 2010. Synthesis of fluorinated hyperbranched polymers capable as highly hydrophobic and oleophobic coating materials. Eur. Polym. J. 46, 506-518.

Taniyasu, S., Kannan, K., Horii, Y., Hanari, N., Yamashita, N., 2003. A survey of perfluorooctane sulfonate and related perfluorinated organic compounds in water, fish, birds, and humans from Japan. Environ. Sci. Technol. 37, 2634-2639.

Taniyasu, S., Senthilkumar, K., Yamazaki, E., Yeung, L.W.Y., Guruge, K.S., Kannan, K., Yamashita, N., 2013. Perfluoroalkyl substances in the blood of wild rats and mice from 47 prefectures in Japan: use of samples from Nationwide Specimen Bank. Arch. Environ. Contam. Toxicol. 65, 149-170.

Thompson, J., Roach, A., Eaglesham, G., Bartkow, M.E., Edge, K., Mueller, J.F., 2011. Perfluorinated alkyl acids in water, sediment and wildlife from Sydney harbour and surroundings. Mar. Pollut. Bull. 62, 2869-2875.

Thumm, S., 2015. Das PFOA-Restriction-Dossier der ECHA; V. Verband der Bayerischen Textil-und Bekleidungsindustrie e.V. Kooperation mit Südwesttextil/Gesamtmasche.

ToxServices LLC, 2013. Paraffin Wax (Melting Point 45 to $48{ }^{\circ} \mathrm{C}$ ) (CAS \#8002-74-2) GreenScreen ${ }^{\mathrm{TM}}$ Assessment (Washington, D.C., USA).

UNEP, 2012. Technical Paper on the Identification and Assessment of Alternatives to the Use of Perfluorooctane Sulfonic Acid in Open Applications (Geneva, Switzerland).

UNEP, 2014. Report on the Assessment of Alternatives to Perfluorooctane Sulfonic Acid, its Salts and Perfluorooctane Sulfonyl Fluoride.

US EPA, 2011. Design for the Environment Program Alternatives Assessment Criteria for Hazard Evaluation Version 2.0. Office of Pollution Prevention \& Toxics, U.S. Environmental Protection Agency (http://www.epa.gov/sites/production/files/2014-01/ documents/aa_criteria_v2.pdf).

US EPA, 2013. 2010/2015 PFOA stewardship program. http://www.epa.gov/oppt/pfoa/ pubs/stewardship/index.html;.
US EPA, 2014. In: programme C.o.t.P.S. (Ed.), 2010/2015 PFOA Stewardship Program 2014 Annual Progress Reports (www.epa.gov).

Van De Vijver, K.I., Hoff, P., Das, K., Brasseur, S., Van Dongen, W., Esmans, E., Reijnders, P., Blust, R., De Coen, W., 2005. Tissue distribution of perfluorinated chemicals in harbor seals (Phoca vitulina) from the Dutch wadden sea. Environ. Sci. Technol. 39, 6978-6984.

Vicente, J., Sanpera, C., García-Tarrasón, M., Pérez, A., Lacorte, S., 2015. Perfluoroalkyl and polyfluoroalkyl substances in entire clutches of Audouin's gulls from the ebro delta. Chemosphere 119, S62-S68 (Supplement).

Vierke, L., Staude, C., Biegel-Engler, A., Drost, W., Schulte, C., 2012. Perfluorooctanoic acid (PFOA) - main concerns and regulatory developments in Europe from an environmental point of view. Environ. Sci. Eur. 24, 1-11.

Wambaugh, J.F., Setzer, R.W., Pitruzzello, A.M., Liu, J., Reif, D.M., Kleinstreuer, N.C., Wang N.C., Sipes, N., Martin, M., Das, K., DeWitt, J.C., Strynar, M., Judson, R., Houck, K.A., Lau, C., 2013. Dosimetric anchoring of in vivo and in vitro studies for perfluorooctanoate and perfluorooctanesulfonate. Toxicol. Sci. 136, 308-327.

Wang, J., Mao, G., Ober, C.K., Kramer, E.J., 1997. Liquid crystalline, semifluorinated side group block copolymers with stable low energy surfaces: synthesis, liquid crystalline structure, and critical surface tension. Macromolecules 30, 1906-1914.

Wang, N., Szostek, B., Buck, R.C., Folsom, P.W., Sulecki, L.M., Gannon, J.T., 2009. 8-2 Fluorotelomer alcohol aerobic soil biodegradation: pathways, metabolites, and metabolite yields. Chemosphere 75, 1089-1096.

Wang, D.G., Norwood, W., Alaee, M., Byer, J.D., Brimble, S., 2013a. Review of recent advances in research on the toxicity, detection, occurrence and fate of cyclic volatile methyl siloxanes in the environment. Chemosphere 93, 711-725.

Wang, Z., Cousins, I.T., Scheringer, M., Hungerbühler, K., 2013b. Fluorinated alternatives to long-chain perfluoroalkyl carboxylic acids (PFCAs), perfluoroalkane sulfonic acids (PFSAs) and their potential precursors. Environ. Int. 60, 242-248.

Wang, Y.J., Niu, J.F., Zhang, L.L., Shi, J.H., 2014. Toxicity assessment of perfluorinated carboxylic acids (PFCAs) towards the rotifer Brachionus calyciflorus. Sci. Total Environ. 491, 266-270

Wang, Z., Cousins, I.T., Scheringer, M., Hungerbuehler, K., 2015. Hazard assessment of fluorinated alternatives to long-chain perfluoroalkyl acids (PFAAs) and their precursors: status quo, ongoing challenges and possible solutions. Environ. Int. 75, 172-179.

Washington, J.W., Ellington, J.J., Jenkins, T.M., Evans, J.J., Yoo, H., Hafner, S.C., 2009. Degradability of an acrylate-linked, fluorotelomer polymer in soil. Environ. Sci. Technol. 43, 6617-6623.

Washington, J.W., Jenkins, T.M., Rankin, K., Naile, J.E., 2015. Decades-scale degradation of commercial, side-chain, fluorotelomer-based polymers in soils and water. Environ. Sci. Technol. 49, 915-923.

Wong, Y.W.H., Yuen, C.W.M., Leung, M.Y.S., Ku, S.K.A., Lam, H.L.I., 2006. Selected applications of nanotechnology in textiles. Autex Res. J. 6.

Yamada, A., Bemrah, N., Veyrand, B., Pollono, C., Merlo, M., Desvignes, V., Sirot, V. Oseredczuk, M., Marchand, P., Cariou, R., Antignac, J.P., Le Bizec, B., Leblanc, J.C., 2014. Perfluoroalkyl acid contamination and polyunsaturated fatty acid composition of French freshwater and marine fishes. J. Agric. Food Chem. 62, 7593-7603.

Zero Discharge of Hazardous Chemicals (ZDHC), 2012. Durable Water and Soil Repellent Chemistry in the Textile Industry - A Research Report. P05 Water Repellency Project.

Zero Discharge of Hazardous Chemicals (ZDHC), 2014. Manufacturing Restricted Substances List. Joint Roadmap Deliverable.

Zhang, J., France, P., Radomyselskiy, A., Datta, S., Zhao, J., van Ooij, W., 2003. Hydrophobic cotton fabric coated by a thin nanoparticulate plasma film. J. Appl. Polym. Sci. 88, 1473-1481. 